\title{
Electronic Nose To Detect Volatile Compound Profile and Quality Changes in 'Spring Belle' Peach (Prunus persica L.) during Cold Storage in Relation to Fruit Optical Properties Measured by Time-Resolved Reflectance Spectroscopy
}

\author{
Anna Rizzolo, ${ }^{* \dagger}$ Giulia Bianchi, ${ }^{\dagger}$ Maristella Vanoli, ${ }^{\dagger}{ }^{\S}$ Susan Lurie, ${ }^{\perp}$ Lorenzo Spinelli, ${ }^{\#}$ \\ and Alessandro Torricelli ${ }^{\S}$ \\ ${ }^{\dagger}$ Consiglio per la Ricerca e Sperimentazione in Agricoltura, Unità di Ricerca per i Processi dell'Industria Agroalimentare, \\ via Venezian 26, 20133 Milano, Italy \\ ${ }^{\S}$ Dipartimento di Fisica, Politecnico di Milano, Piazza Leonardo da Vinci 32, 20133 Milano, Italy \\ \#Istituto di Fotonica e Nanotecnologie, CNR, Piazza Leonardo da Vinci 32, 20133 Milano, Italy \\ ${ }^{\perp}$ Postharvest Science, Agricultural Research Organization, The Volcani Center, P.O. Box 6, 50250 Bet Dagan, Israel
}

\begin{abstract}
The aim of this research was to study the relationships between electronic nose (E-nose) pattern, maturity class of peaches assessed at harvest by means of absorption coefficient at $670 \mathrm{~nm}\left(\mu_{\mathrm{a}} 670\right)$ measured in fruit pulp by time-resolved reflectance spectroscopy (TRS), and quality evolution during a 4 week cold storage. 'Spring Belle' peaches were measured for $\mu_{\mathrm{a}} 670$ by TRS, ranked according to decreasing $\mu_{\mathrm{a}} 670$ value, divided into three TRS maturity classes (less (LeM), medium $(\mathrm{MeM})$, and more (MoM) mature), and randomized into 9 samples of 30 fruit each, so that fruits from the whole $\mu_{\mathrm{a}} 670$ range were present in each sample. At harvest and after 1, 2, 3, and 4 weeks of storage at 0 and $4{ }^{\circ} \mathrm{C}$, fruits of each sample were evaluated for firmness, expressible juice, $\mu_{\mathrm{a}} 670$, and ethylene production. LeM and MoM peaches of each sample were analyzed for aroma pattern by a commercial electronic nose and by static HS-GC and for sugar (glucose, fructose, sucrose, and sorbitol) and organic acid (quinic, malic, and citric acids) compositions by HPLC. Principal component analysis (PCA) of electronic nose data emphasized the ability of the E-nose to assess the ripening stage of fruit associated with maturity class, storage time, and storage temperature. The sensors having the highest influence on the pattern were W5S in PC-1, W1S in PC-2, and W2S in PC-3. From linear correlation analysis between PCs and firmness, flavor, and volatile compounds, it was found that PC-1 was related to ethylene production and volatile compounds (mainly acetate esters and ethanol); the highest PC-1 scores were found for fruit belonging to the MoM class after 2 weeks of storage at $4{ }^{\circ} \mathrm{C}$, which showed the rise in ethylene production coupled with the highest total volatile production and sugar and acid composition of ripe peach fruits. PC- 2 correlated with hexanal, ethyl acetate, and sugar composition, and PC-3 was mainly related to flavor compounds; both functions significantly changed with cold storage time in different ways according to storage temperature and maturity class.
\end{abstract}

KEYWORDS: peaches, volatile compounds, sugar and acid composition, cold storage, TRS maturity class, electronic nose

\section{INTRODUCTION}

Peach (Prunus persica L.) is one of the most appreciated fruits by consumers for its juicy texture, high nutrient content, and pleasant flavor. It is a climacteric fruit in which ethylene regulates many ripening-related processes, such as flesh softening, chlorophyll loss, and/or carotenoid and anthocyanin accumulation and modifications of sugars, acids, and volatile profiles. ${ }^{1}$ All of these processes influence the appearance, texture, flavor, and aroma, that is, the overall fruit quality. Sucrose, citric acid, malic acid, carotenoids, and lactones as well as polyphenol and pectic substances determine the sensory quality and nutritive values of the fruits. ${ }^{2}$ Some of these compounds are important antioxidants, and their levels have relevant health implications. The concentration, type, and interaction of individual sugars and organic acids are well correlated to peach taste, and the emission of specific volatile compounds is closely related to aroma perception., ${ }^{3,4}$ Sugar, organic acid, and volatile compositions of peach and nectarines depend on cultivar, ${ }^{5,6}$ maturity stage, $^{5,7-9}$ and postharvest handling and storage conditions. ${ }^{4,10-14}$
It is well-known that peach quality is strictly dependent on fruit maturity. If harvested ripe, peaches have excellent eating quality, because sugars and flavor components increase while organic acids decrease with ripening. ${ }^{9,15}$ However, ripe peaches are juicy and soft and therefore more susceptible to bruising and decay during handling and transport. For this reason, peaches are commonly picked at an early stage of ripening and do not always reach full flavor and aroma. ${ }^{16,17}$

Therefore, there is a great interest in improving the assessment of peach maturity, currently based on Magness-Taylor firmness (destructive, highly variable, and time-consuming) and color (not reliable for highly colored varieties). ${ }^{18}$ As an alternative, in recent years there has been an increasing interest in the

Special Issue: IX Italian Congress of Food Chemistry

Received: June 29, 2012

Revised: September 26, 2012

Accepted: September 29, 2012

Published: September 29, 2012 
development of nondestructive techniques, and several authors have studied chlorophyll-related spectral indices, finding good correlations with maturity degree in peaches. Chlorophyll absorption at $670-680 \mathrm{~nm}$, in fact, can be considered the single spectrum area directly related to fruit ripening and not affected by other pigments. ${ }^{18,19}$ The absorption at $670 \mathrm{~nm}$ in the fruit pulp is actually measured by time-resolved reflectance spectroscopy (TRS).

TRS is a nondestructive technique based on the measurement of the temporal delay and broadening experienced by a short laser pulse (pulse duration on the order of $100 \mathrm{ps}$ ) while traveling through a turbid medium, such as fruit flesh. ${ }^{20}$ By using an appropriate theoretical model of light penetration for the analysis of photon time distribution, it is possible to simultaneously estimate the absorption coefficient $\left(\mu_{\mathrm{a}}\right)$ and the reduced scattering coefficient $\left(\mu_{s}^{\prime}\right)$. The absorption and reduced scattering coefficients correspond, respectively, to the probability (per unit distance traveled by a photon) of being absorbed by the main fruit components (water, chlorophyll, carotenoids, and sugars) and of changing direction due to microscopic changes in refractive index caused by membranes, air, vacuoles, or organelles. TRS probes fruits and vegetables to a depth as great as $1-2 \mathrm{~cm}$, depending on the optical properties. ${ }^{21}$

The absorption coefficient measured at $670 \mathrm{~nm}\left(\mu_{\mathrm{a}} 670\right)$ has been shown to be an effective maturity index for nectarines: it is related to fruit biological age and decreases with ripening in early- and late-maturing nectarines. ${ }^{22,23}$ The decrease of $\mu_{\mathrm{a}} 670$ follows a logistic curve and is synchronized with softening, although some seasonal variations occur: softening occurs earlier in fruit showing low $\mu_{\mathrm{a}} 670$ at harvest (more mature fruit) and later in high $\mu_{\mathrm{a}} 670$ fruit (less mature fruit). ${ }^{22,24}$ The conversion of $\mu_{\mathrm{a}} 670$ to the biological shift factor allowed the selection of nectarines for different market destinations and was successfully applied in an export trial from Italy to The Netherlands, simulating on a small scale the fruit supply chain from packing-house to consumer. ${ }^{25}$ By using $\mu_{\mathrm{a}} 670$ it was possible to select nectarines having different ethylene production rates at harvest and during shelf life, along with distinctive sugar, acid, and aroma compositions. Total sugars, percent sucrose, and percent malic and quinic acid increased, whereas percent fructose, sorbitol, total acids, and especially citric acid decreased, with decreasing $\mu_{\mathrm{a}} 670 .{ }^{26}$ At the same time, low $\mu_{\mathrm{a}} 670$ nectarines reached earlier the climacteric peak and developed a fruity, lactonic, peach-like aroma. ${ }^{27,28}$

In peaches, quality characteristics change quickly and deteriorate at ambient temperature, so cold storage is used to slow ripening processes and decay development. However, peaches stored at low temperature can easily develop chilling injury (CI): fruit becomes dry, mealy, woolly, or hard textured with no juice, with flesh browning and/or reddening. ${ }^{29} \mathrm{CI}$ is genetically influenced and triggered by a combination of storage temperature and storage period: CI symptoms develop faster at temperatures between 2.2 and $7.6^{\circ} \mathrm{C}$, but become less intense and develops later when fruits are stored at $0{ }^{\circ} \mathrm{C}$. Lurie et al. ${ }^{30}$ found that $\mu_{\mathrm{a}} 670$ decreased in fruit stored at $0{ }^{\circ} \mathrm{C}$ for the first 3 days at $20^{\circ} \mathrm{C}$ of shelf life, whereas it increased in fruit from $4{ }^{\circ} \mathrm{C}$ storage due to the appearance of $\mathrm{CI}$.

The assessment of the ripening process of fruits and vegetables from harvest to consumption could be carried out using electronic noses. ${ }^{31}$ The electronic nose (E-nose) is based on inexpensive, nonspecific solid-state sensors, which are sensitive to the volatile compounds emitted in the headspace atmosphere by the sample. ${ }^{32}$ The signals from the individual sensors are analyzed by chemometrics tools, such as linear discriminant analysis, principal component analysis, and partial least-squares to have dimensionality reduction of the data set, which, therefore, can be examined in a two- or three-dimensional plots. ${ }^{33}$ Samples with similar odors generally but not always give rise to similar patterns, and samples with different odors represent differences in their patterns. A drawback for the E-nose systems is that they are also affected by the environmental conditions (temperature and humidity), which can cause sensor drift, even if calibration systems and built-in algorithms help compensate for this. $^{32}$

Promising results of E-nose technology have been obtained for discrimination among peach and nectarine cultivars, ${ }^{34,35}$ for the assessment of ripening stage, ${ }^{34,37}$ and for the differentiation of stored from unstored peach fruit and of peach fruit subjected to different temperatures and storage periods, discriminating CI fruit from healthy ones. ${ }^{13,35}$ Furthermore, Di Natale et al. ${ }^{37}$ and Zhang et al. ${ }^{38}$ studied the performance of two types of E-nose in predicting quality characteristics, such as flesh firmness, soluble solids content, and titratable acidity.

Even though a lot of research has been carried out during recent years on the quality characteristics of peaches and nectarines, to our knowledge the specific relationships between E-nose pattern, flavor, and volatile evolution during cold storage of peaches of different maturity stages are not yet studied in depth. Hence, this research aimed at studying these relationships by using a commercial E-nose based on a 10 metal oxide semiconductor (MOS) sensor array coupled to the nondestructive assessment of ripening degree as assessed by TRS on an earlymaturing peach cultivar cold-stored up to 4 weeks at two temperatures.

\section{MATERIALS AND METHODS}

Plant Material and Experimental Plan. The experiment was carried out on peaches (P. persica L.) cv. 'Spring Belle', a mutant of the better known 'Springcrest' peach cultivar, which ripens early during the season (June), with fruit having high carotenoid and polyphenol contents both at harvest and after storage, coupled to a juicy texture with a good taste, even if with high acidity. ${ }^{39}$ Peaches were harvested on June 22, 2010, in a commercial orchard in Faenza (Italy). On the next day, 270 fruits without defects or bruises were selected and labeled, individually measured by TRS at $670 \mathrm{~nm}$, and hence ranked according to decreasing $\mu_{\mathrm{a}} 670$ value, that is, from the less to the more mature ones. The ranked fruits were grouped by nines, with a total of 30 groups, corresponding to 30 levels of $\mu_{\mathrm{a}} 670$. Each fruit from each group was randomly assigned to a different sample. In this way, 9 samples were obtained, each one containing 30 fruits from the whole range of $\mu_{\mathrm{a}} 670$. In each sample, according to fruit ranking, the 30 fruits were divided into three TRS maturity classes: less mature (LeM, rank 1-10), medium mature (MeM, rank 11-20), and more mature (MoM, rank 21-30). Each sample was used for a single time of analysis: one at harvest (sample 1), and the others for the cold storage samplings after $1,2,3$, and 4 weeks of storage at $0{ }^{\circ} \mathrm{C}(\mathrm{RH} \approx 70 \%)$ (samples $2-5)$ and at $4{ }^{\circ} \mathrm{C}(\mathrm{RH} \approx 90 \%)$ (samples $\left.6-9\right)$. Hereafter fruits of each TRS maturity class stored at $0{ }^{\circ} \mathrm{C}$ are referred to as LeM_OC, MeM_OC, and MoM_0C and those stored at $4{ }^{\circ} \mathrm{C}$ as LeM_4C, MeM_4C, and MoM_4C.

At harvest and after storage at either 0 or $4{ }^{\circ} \mathrm{C}$, all fruits of each sample were evaluated for $\mu_{\mathrm{a}} 670$, firmness, and expressible juice, whereas the 15 fruits having an odd ranking number were analyzed for ethylene production by gas chromatography (GC). Then, for each sample, peaches of LeM and MoM maturity classes were divided into two subsamples of five fruit, which were sliced, pooled, immediately deep frozen, and kept at $-30{ }^{\circ} \mathrm{C}$ until analysis of volatile pattern by E-nose and static headspace gas chromatography (static-HS-GC) and of sugar (glucose, fructose, sucrose, and sorbitol) and organic acid 
(quinic, malic, and citric acids) compositions by high-performance liquid chromatography (HPLC).

Chemicals. Acetaldehyde, ethanol, methyl acetate, ethyl acetate, hexanal, (E)-2-hexenal, benzaldehyde, (Z)-3-hexenol, hexyl acetate, $(Z)$-3-hexenyl acetate, $(E)$-2-hexenyl acetate, and $\gamma$-decalactone were obtained from Fluka Chemie (Buchs, SG, Switzerland); hexanol was supplied by VWR International $\mathrm{GmbH}$ (Darmstadt, Germany), $\gamma$-hexalactone by TCI (Tokyo, Japan), and $\gamma$-dodecalactone by Sigma-Aldrich s.r.l. (Milano, Italy). All other chemicals and reagents used were of analytical grade. Water was obtained from a Milli-Q apparatus (Millipore, Milford, MA).

TRS Measurements. The absorption coefficient at $670 \mathrm{~nm}$ $\left(\mu_{2} 670\right)$ was measured by TRS on two sides of each fruit (blush and nonblush sides) and then averaged per fruit. The instrument used for TRS was a portable prototype for time-resolved reflectance measurements at discrete wavelengths. The light source is a pulsed laser diode (model PDL800, PicoQuant GmbH, Germany) working at $670 \mathrm{~nm}$, with $80 \mathrm{MHz}$ repetition frequency, 100 ps duration, and $1 \mathrm{~mW}$ average power. A compact photomultiplier (model R5900U-L16, Hamamatsu Photonics, Japan) and an integrated PC board for time-correlated single photon counting (model SPC130, Becker \& Hickl GmbH, Germany) are used to detect TRS data. Typical acquisition time is $1 \mathrm{~s}$ per point. A couple of $1 \mathrm{~mm}$ plastic fibers (model ESKA GK4001, Mitsubishi, Japan) delivers light into the sample and collects the emitted photons. A band-pass filter tuned at the laser wavelength is used to cut off the fluorescence signal due to chlorophyll or inks. Overall, the instrumental response function duration is $<180$ ps. A home-built holder allowed the fibers to be positioned $1.5 \mathrm{~cm}$ apart, parallel to each other, normal to and in contact with the sample surface. A detailed description of the system can be found in Cubeddu et al. ${ }^{21}$

Firmness. Firmness was measured by a penetrometer (Texture Analyzer TA.Xtplus, Stable Micro Systems, UK; $8 \mathrm{~mm}$ diameter plunger, crosshead speed of $3.33 \mathrm{~mm} \mathrm{~s}^{-1}$ ) after skin removal, in positions corresponding to the two TRS readings.

Expressible Juice. Expressible juice is used for mealiness assessment in peaches and nectarines and correlates with visual mealiness assessment. ${ }^{40}$ A plug was removed from each fruit, and a $1 \mathrm{~cm}$ section just below the peel was taken, placed in a syringe, and gently disrupted by extruding it by forcing it through a luer hub. After disruption, collected tissue was centrifuged at $12000 \mathrm{~g}$ for $10 \mathrm{~min}$, and the volume of the supernatant was recorded as a percentage of the initial tissue mass.

Ethylene Production Rate (EPR). The EPR was measured on the 15 fruits of each sample having an odd ranking number. Fruits were put in $1.7 \mathrm{~L}$ gastight glass jars (one fruit per jar) for $1 \mathrm{~h}$ at $20^{\circ} \mathrm{C}$; then, $1 \mathrm{~mL}$ of the headspace gas was sampled and analyzed for the ethylene content following the conditions reported by Rizzolo and Visai ${ }^{41}$ using a deactivated aluminum oxide F1 (80-100 mesh) column $(1 / 8$ in. $X$ $200 \mathrm{~cm}$ ); column temperature, $100^{\circ} \mathrm{C}$; injection temperature, $100{ }^{\circ} \mathrm{C}$; and FID temperature, $225{ }^{\circ} \mathrm{C}$. Quantitative data were obtained by relating ethylene peak area to that of a $10 \mu \mathrm{L} \mathrm{L}^{-1}$ standard and were expressed as picomoles per kilogram per second; GC data were corrected for fruit mass, empty volume of the jar, and time of production.

Preparation of Pulp Samples for Volatile Pattern Analyses and Sugar and Organic Acid Compositions. Pulp samples for analyses of aroma pattern by E-nose and static-HS-GC and sugar and organic acid compositions by HPLC were prepared from each subsample of LeM and MoM maturity classes by allowing the frozen slices to thaw at room temperature for about $1 \mathrm{~h}$ and homogenizing them for $1 \mathrm{~min}$ in a commercial food processor (Moulinex, Paris, France). Then $10 \mathrm{~g}$ aliquots of pulp purée were taken for volatile pattern analyses (three replicates), for GC-MS analysis (two replicates), and for sugar and organic acid analyses (two replicates). Replicates for volatile pattern and GC-MS analyses were prepared by putting $10 \mathrm{~g}$ pulp aliquots into $25 \mathrm{~mL}$ vials and insufflating nitrogen prior to tightly closing them with an aluminum cap with a silicone-Teflon rubber septum; then samples were immediately frozen and kept at $-30{ }^{\circ} \mathrm{C}$ until the headspace GC analysis. Each replicate for sugar and organic acid composition analysis was immediately submitted to extraction.

Analysis of Volatile Compounds. The analysis of volatile compounds by a static headspace method ${ }^{42}$ was performed on each replicate after a 30 min thawing at room temperature and the E-nose analysis. Each vial was heated at $70{ }^{\circ} \mathrm{C}$ for $30 \mathrm{~min}$, and $0.5 \mathrm{~mL}$ of the headspace gas was sampled and injected using the automatic headspace sampler HSS 86.50 DANI (DANI Instruments SpA, Cologno Monzese, Italy) fitted to a gas chromatograph DANI 8521, equipped with a PTV injector port operating in splitless mode, a FID detector, and a DB-1 column $(60 \mathrm{~m} \times 0.53 \mu \mathrm{m}$ i.d., $1 \mu \mathrm{m}$ film thickness $)$. The following GC conditions were used: helium carrier gas flow rate,

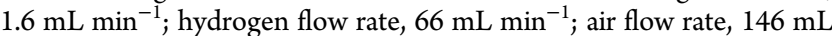
$\mathrm{min}^{-1}$; oven temperature program, $10 \mathrm{~min}$ at $50{ }^{\circ} \mathrm{C}, 2.5^{\circ} \mathrm{C} \mathrm{min}^{-1}$ to $90{ }^{\circ} \mathrm{C}, 1 \mathrm{~min}$ at $90{ }^{\circ} \mathrm{C}, 4{ }^{\circ} \mathrm{C} \mathrm{min}{ }^{-1}$ to $198{ }^{\circ} \mathrm{C}$; injector port and detector temperatures, 200 and $250^{\circ} \mathrm{C}$, respectively.

Volatile compounds were identified by comparison with GC-MS data obtained by SPME-HS sampling with a DVB/CAR/PDMS fiber (Supelco) at $45^{\circ} \mathrm{C}$ for $30 \mathrm{~min}^{6}$ and a desorption time of 2 min using an Agilent $6890 \mathrm{~N}$ GC (Agilent Technologies Italia SpA, Cernusco s/N, Italy) linked to an Agilent $5973 \mathrm{~N}$ mass selective detector. Separation was achieved on a DB-1 column $(60 \mathrm{~m} \times 0.25 \mu \mathrm{m}$ i.d., $0.25 \mu \mathrm{m}$ film thickness) using the following conditions: carrier gas, helium, flow rate, $0.9 \mathrm{~mL} \mathrm{~min}^{-1}$; temperature program, $5 \mathrm{~min}$ at $50{ }^{\circ} \mathrm{C}$, $2{ }^{\circ} \mathrm{C} \mathrm{min}{ }^{-1}$ to $240{ }^{\circ} \mathrm{C}, 20 \mathrm{~min}$ at $240{ }^{\circ} \mathrm{C}$; injector and detector temperatures, 200 and $240{ }^{\circ} \mathrm{C}$, respectively; interconnecting line temperature, $250{ }^{\circ} \mathrm{C}$. The MS settings were as follows: filament voltage, $70 \mathrm{eV}$; scan range, 40-400 amu; scan speed, $1.4 \mathrm{scan} \mathrm{s}^{-1}$. Identification was performed by comparing mass spectra with those of a database (NBS mass spectral library), retention index, and standard compounds.

The quantification was obtained by relating the peak area of each one to that of external standards, which were prepared by adding known amounts of standard compounds to $10 \mathrm{~mL}$ of water, sealing, and analyzing them in the same way as fruit samples. Data were expressed as micrograms per kilogram fresh weight (FW) of pulp. The unknown and the tentatively identified volatile compounds were quantified by relating their peak area to that of the hexyl acetate external standard.

Electronic Nose. The PEN3 portable electronic nose (Win Muster Airsense Analytics Inc., Germany) consists of a sampling section, a detector unit containing the array of sensors, and pattern recognition software (Win Muster v.3.0) for data recording and elaboration. The sensor array is composed of 10 metal oxide semiconductor (MOS) type chemical sensors: W1C (aromatic), W5S (broadrange), W3C (aromatic), W6S (hydrogen), W5C (aromatic aliphatics), W1S (broad methane), W1W (sulfur organic), W2S (broad alcohol), W2W (sulfur chlorinate), and W3S (methane aliphatics). The sensor response is given by the ratio of the conductivity response of the sensors to the sample gas $(G)$ relative to the carrier gas $\left(G_{0}\right)$ over time $\left(G / G_{0}\right)$.

The E-nose analyses were performed immediately before the GC analyses on the same samples, after $30 \mathrm{~min}$ of thawing at room temperature, and were carried out in a room kept at $20 \pm 1{ }^{\circ} \mathrm{C}$ and $50-60 \%$ realtive humidity $(\mathrm{RH})$ to minimize sensor drift, which is known to be caused by changes in environmental conditions (temperature and humidity). ${ }^{32}$ The headspace gas was pumped over the sensor surfaces for $60 \mathrm{~s}$ (injection time) at a flow rate of $45 \mathrm{~mL}$ $\min ^{-1}$, and during this time the sensor signals were recorded. After sample analysis, the system was purged for $120 \mathrm{~s}$ with filtered air prior to the next sample injection to allow re-establishment of the instrument baseline. Each sample was evaluated three times. For each E-nose run, the conductivity $G / G_{0}$ of the 10 sensors at the time corresponding to the normalized maximum of all signals was taken as the vector of sensors signal. The average of the runs of each replicate was used for statistical analysis.

Sugar and Organic Acid Composition. Sugars (sucrose, fructose, glucose, and sorbitol) and organic acids (malic, quinic, and citric acids) were analyzed by HPLC on the aqueous extract of fruit pulp, obtained by homogenizing $10 \mathrm{~g}$ aliquots of pulp puree in $30 \mathrm{~mL}$ of water, centrifuging the mixture at $6000 \mathrm{rpm}(4670 \mathrm{~g})$ for $15 \mathrm{~min}$, and filtering the supernatant through glass wool into a $100 \mathrm{~mL}$ volumetric 
Table 1. Absorption Coefficient at $670 \mathrm{~nm}\left(\mu_{\mathrm{a}} 670\right)$, Firmness, and Expressible Juice of 'Spring Belle' Peaches according to TRS Maturity Class at Harvest (0) and after 1, 2, 3, and 4 Weeks of Storage at 0 and $4{ }^{\circ} \mathrm{C}$

\begin{tabular}{|c|c|c|c|c|c|c|c|c|c|}
\hline \multirow[b]{2}{*}{ weeks of storage } & \multicolumn{3}{|c|}{$\mu_{\mathrm{a}} 670\left(\mathrm{~cm}^{-1}\right)$} & \multicolumn{3}{|c|}{ firmness (N) } & \multicolumn{3}{|c|}{ expressible juice (\%) } \\
\hline & $\operatorname{LeM}^{a}$ & $\mathrm{MeM}^{a}$ & $\mathrm{MoM}^{a}$ & LeM & $\mathrm{MeM}$ & MoM & LeM & $\mathrm{MeM}$ & MoM \\
\hline \multicolumn{10}{|l|}{ harvest } \\
\hline 0 & $0.247(0.009)^{b}$ & $0.182(0.003)$ & $0.137(0.008)$ & 48.35 (2.39) & $31.41(3.35)$ & $15.24(3.20)$ & $58.0(2.0)$ & $64.7(1.2)$ & $68.8(0.9)$ \\
\hline \multicolumn{10}{|l|}{ storage at $0{ }^{\circ} \mathrm{C}$} \\
\hline 1 & $0.249(0.010)$ & $0.185(0.005)$ & $0.135(0.006)$ & $46.17(2.64)$ & $39.80(3.31)$ & $13.19(1.45)$ & $61.3(1.7)$ & $62.9(0.8)$ & $66.3(1.4)$ \\
\hline 2 & $0.241(0.011)$ & $0.183(0.004)$ & $0.131(0.007)$ & $50.56(1.37)$ & $33.97(3.84)$ & $13.42(2.57)$ & $52.1(2.2)$ & $59.8(1.1)$ & $64.1(1.2)$ \\
\hline 3 & $0.228(0.013)$ & $0.168(0.004)$ & $0.126(0.005)$ & $45.97(2.58)$ & $37.92(5.31)$ & 14.39 (2.89) & $59.7(1.2)$ & $58.6(1.1)$ & $65.8(1.7)$ \\
\hline 4 & $0.202(0.007)$ & $0.149(0.005)$ & $0.108(0.004)$ & $47.22(2.67)$ & $33.08(3.64)$ & $10.83(2.53)$ & $59.7(1.2)$ & $62.9(0.9)$ & $67.9(1.1)$ \\
\hline \multicolumn{10}{|l|}{ storage at $4{ }^{\circ} \mathrm{C}$} \\
\hline 1 & $0.234(0.013)$ & $0.173(0.003)$ & $0.123(0.005)$ & $35.87(3.42)$ & $24.67(2.05)$ & $7.62(3.08)$ & $61.8(0.7)$ & $63.8(0.7)$ & $69.0(1.5)$ \\
\hline 2 & $0.190(0.008)$ & $0.137(0.005)$ & $0.095(0.006)$ & $25.36(3.42)$ & $9.25(1.45)$ & $4.34(0.23)$ & $60.3(1.1)$ & $63.5(14)$ & $70.3(1.6)$ \\
\hline 3 & $0.148(0.010)$ & $0.101(0.007)$ & $0.076(0.005)$ & $13.29(2.54)$ & $5.37(0.96)$ & $3.32(0.10)$ & $59.1(1.7)$ & $65.9(2.2)$ & $71.3(1.5)$ \\
\hline 4 & $0.104(0.004)$ & $0.076(0.003)$ & $0.065(0.002)$ & $6.23(1.30)$ & $4.61(0.77)$ & $2.99(0.02)$ & $62.9(1.4)$ & 70.9 (1.6) & $76.8(1.0)$ \\
\hline \multicolumn{10}{|l|}{ main effects ${ }^{c}$} \\
\hline mat (A) & & $* * *$ & & & $* * *$ & & & $* * *$ & \\
\hline time (B) & & $* * *$ & & & *** & & & $* * *$ & \\
\hline temp (C) & & $* * *$ & & & $* * *$ & & & $* * *$ & \\
\hline \multicolumn{10}{|l|}{ interactions } \\
\hline$A \times B$ & & $* * *$ & & & *** & & & ns & \\
\hline$A \times C$ & & $* *$ & & & $* * *$ & & & ns & \\
\hline $\mathrm{B} \times \mathrm{C}$ & & $* * *$ & & & $* * *$ & & & $* * *$ & \\
\hline $\mathrm{A} \times \mathrm{B} \times \mathrm{C}$ & & ns & & & $* * *$ & & & $\mathrm{~ns}$ & \\
\hline
\end{tabular}

${ }^{a}$ TRS maturity classes: LeM, less mature; MeM, medium mature; MoM, more mature. ${ }^{b}$ Numbers in parentheses are the standard error of the mean $(n=10) .{ }^{c} P$ value of $F$ ratio: ns, not significantly different; $*, P<0.05$; $* *, P<0.01$; $* * *, P<0.001$. mat, maturity class; time, storage time; temp, storage temperature

flask. The pellet following centrifugation was mixed with $30 \mathrm{~mL}$ of water and centrifuged, and the resulting supernatant was combined with the initial one and brought to the mark. Before HPLC analyses, the extracts were filtered through a $0.45 \mu \mathrm{m}$ Nylon 66 membrane unit with a $1 \mu \mathrm{m}$ glass wool prefilter unit. $^{10,43}$

The chromatographic system for sugar composition (sucrose, fructose, glucose, and sorbitol) analysis consisted of a Jasco AS-1555 intelligent sampler (Jasco Co., Tokyo, Japan), a Jasco PU 880 pump, a $300 \times 7.8 \mathrm{~mm}$ i.d., $8 \mu \mathrm{m}$, BP-100-Ca ${ }^{2+}$ carbohydrate column (Benson Polymeric Inc., Sparks, NV, USA) kept at $85^{\circ} \mathrm{C}$, and a Jasco RI-930 intelligent refractive index detector. The volume of injection was $10 \mu \mathrm{L}$, and the mobile phase was HPLC grade water at a flow rate of $0.6 \mathrm{~mL}$ $\mathrm{min}^{-1}$. The quantification was obtained by relating the peak area of each sugar to that of its external standard, and data were expressed as grams per kilogram FW.

The chromatographic system for organic acid composition (quinic acid, malic acid, and citric acid) analysis consisted of a Jasco AS-155510 intelligent sampler, a Jasco PU 980 pump, a $250 \times 4.6 \mathrm{~mm}$ i.d., $5 \mu \mathrm{m}$ particle size, Inertsil ODS-3 column (GL Sciences, Inc., Sinjuku-Ku, Tokyo, Japan) kept at $30{ }^{\circ} \mathrm{C}$, and a Jasco UV 1570 Intelligent UV-vis detector set at $210 \mathrm{~nm}$. The volume of injection was $10 \mu \mathrm{L}$, and the mobile phase was $0.02 \mathrm{M}$ orthophosphoric acid at a flow rate of $0.7 \mathrm{~mL} \mathrm{~min}{ }^{-1}$. The quantification was obtained by relating the peak area of each compound to that of the external standard, and data were expressed as grams per kilogram FW.

Total sugars and total acids were computed as the sums of the individual sugars and acids. The proportions of each individual sugar or acid to the total sugars or acids and the ratio total sugar to total acids $(\mathrm{Su} / \mathrm{Ac})$ were also calculated.

Statistical Analysis. Analysis of variance (ANOVA) was performed using the Statgraphics version 7 (Manugistic Inc., Rockville, MD, USA) software package. Data were submitted to multifactorial analysis of variance considering maturity class, storage time, and storage temperature as a source of variation, and means were compared by Tukey's test at $P \leq 0.05 \%$. Principal component analysis (PCA) was used to extract information from the sensor data to explore the data structure, the relationship between objects, the relationship between objects and variables, and the global correlation of the variables. PCA was performed on a data matrix of 40 rows (one row/ peach sample, using for each sample the average sensor responses of the three replicates) and 10 columns (electronic nose variables) by The Unscrambler $\mathrm{X}$ version 10.0.1 (CAMO, Oslo, Norway) software package using the nonlinear iterative partial least-squares (NIPALS) algorithm. The principal component (PC) scores were then submitted to ANOVA, and means were compared by Tukey's test at $P \leq 0.05 \%$ considering as factors maturity class, storage time, and storage temperature. Correlations between PC and volatile compounds, ethylene, firmness, and organic acid and sugar compositions data were also studied.

\section{RESULTS AND DISCUSSION}

Absorption Coefficient at $670 \mathrm{~nm}$. At harvest the $\mu_{\mathrm{a}} 670$ values ranged from $0.286 \mathrm{~cm}^{-1}$ for the least mature fruit to $0.059 \mathrm{~cm}^{-1}$ for the most mature one: these values were comparable to those found in the early nectarine cultivars 'Spring Bright' and 'Ambra' in previous seasons. ${ }^{22}$ In all three maturity classes, the $\mu_{\mathrm{a}} 670$ changes with storage time depended on storage temperature (Table 1): at $0{ }^{\circ} \mathrm{C}$ in LeM and MoM fruit it significantly decreased only at the end of storage (week 4), whereas in MeM it constantly decreased starting from week 3. In contrast, at $4{ }^{\circ} \mathrm{C}, \mu_{\mathrm{a}} 670$ did not change until week 1 of storage independent of maturity class; then, it constantly decreased in LeM and MeM fruits until the end of storage, and in MoM fruits imtil week 3 . The $\mu_{\mathrm{a}} 670$ values observed at the end of storage indicate that $\mathrm{MoM}$ fruit stored at $0{ }^{\circ} \mathrm{C}$ reached a maturity degree not different from that of LeM fruit stored at $4{ }^{\circ} \mathrm{C}$ and that LeM fruits stored at $0{ }^{\circ} \mathrm{C}$ were the least mature and $\mathrm{MoM}$ ones stored at $4{ }^{\circ} \mathrm{C}$ the most mature.

Firmness and Expressible Juice. At harvest LeM fruit were firmer than MeM and MoM ones, with MoM showing the lowest firmness value (Table 1). These differences were maintained during the storage period. On average, firmness was 


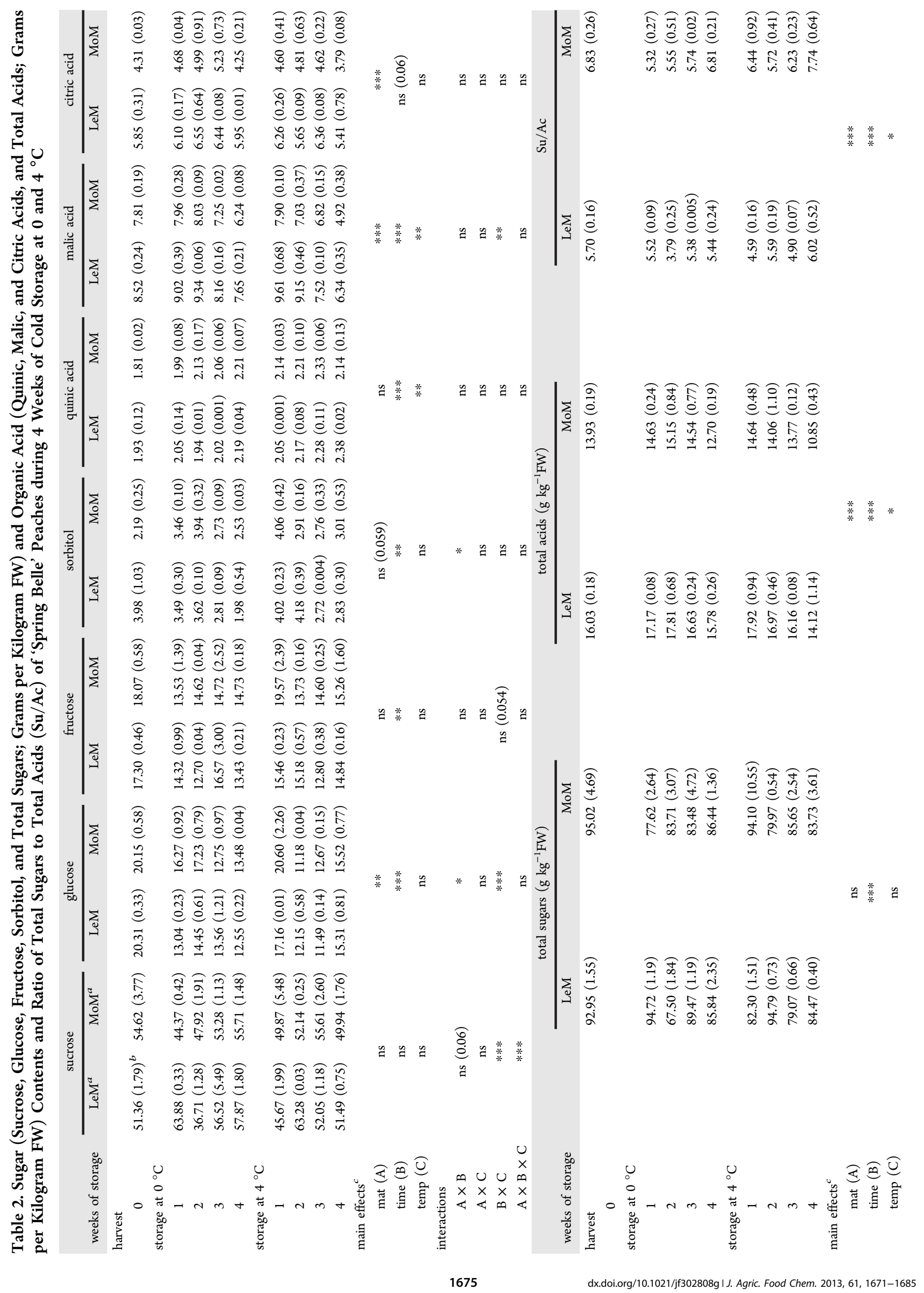


higher in fruits stored at $0{ }^{\circ} \mathrm{C}$ than in those stored at $4{ }^{\circ} \mathrm{C}$. Firmness did not significantly change with storage at $0{ }^{\circ} \mathrm{C}$, whatever the maturity class, whereas at $4{ }^{\circ} \mathrm{C}$ firmness significantly decreased already after 1 week of storage in LeM and MoM classes and after 2 weeks of storage in MeM. Then, it further decreased after 3 weeks of storage only in LeM fruit. The different behaviors of softening according to the TRS maturity class are in agreement with Eccher Zerbini et al.'s ${ }^{24}$ findings, who observed that higher $\mu_{\mathrm{a}} 670$ values corresponded to higher firmness values and lower $\mu_{\mathrm{a}} 670$ values to lower firmness values, with softening at $20{ }^{\circ} \mathrm{C}$ occurring earlier in low $\mu_{\mathrm{a}} 670$ nectarines and later in high $\mu_{\mathrm{a}} 670$ fruits, although in our work softening occurred during the storage period and not during shelf life.

Cano Salazar et al., ${ }^{14}$ Eccher Zerbini et al., ${ }^{23}$ and Dagar et $\mathrm{al}^{44}$ observed that firmness changes very little during storage at $0{ }^{\circ} \mathrm{C}$, whereas it changes more rapidly at $5{ }^{\circ} \mathrm{C}$. A firmness retention or increase after a long storage period, coupled to low expressible juice values, is a typical CI symptom (uneven ripening and dry texture characteristic of woolliness).

Firmness and expressible juice data (Table 1) indicate that 'Spring Belle' cultivar did not develop woolliness with cold storage, even at the higher temperature. In fact, percent expressible juice showed similar values at harvest and after storage at both temperatures. Expressible juice changed with maturity degree: at harvest it was lower in LeM and higher in MoM fruits and either did not change (LeM_0C, MoM_0C and LeM_4C) or increased (MeM_4C and MoM_4C) with storage time. Only in MeM_oC $\overline{\text { did }}$ percent expressible juice show lower values with respect to harvest after 2 and 3 weeks of storage, even if with a mean value of about $59 \%$ comparable with the value observed at harvest for the LeM class.

Sugar and Organic Acid Compositions. Sugars and organic acids are responsible of fruit taste and have an impact on the overall eating quality of the fruit together with aroma. In fact, Colaric et al. ${ }^{3}$ reported that total sugars, sucrose, sorbitol, malic acid, and malic/citric acid ratio have an important influence on peach taste, whereas total organic acids, sucrose, sorbitol, and malic acid strongly affected the aroma perception. The same authors ${ }^{3}$ found that sweetness was negatively correlated with citric acid and positively with sugars/organic acids ratio, and not with sugars, whereas sourness was reliably linked with organic acids and $\mathrm{pH}$.

In our experiment, total sugars decreased from about $94 \mathrm{~g}$ $\mathrm{kg}^{-1}$ at harvest to about $85 \mathrm{~g} \mathrm{~kg}^{-1}$ at the end of cold storage, and total acids significantly decreased from about $15 \mathrm{~g} \mathrm{~kg}^{-1}$ at harvest to $13 \mathrm{~g} \mathrm{~kg}^{-1}$ after 4 weeks (Table 2). Sucrose, which is important in ripe peaches as a sweetener, was the main sugar in 'Spring Belle' peaches, accounting for 58-64\% of total sugars, and it was not influenced by maturity class, storage time, or temperature, even if the interaction among the three factors was significant $(P<0.001)$ : LeM_0C showed a lower amount of sucrose of about $37 \mathrm{~g} \mathrm{~kg}^{-1}$ at week 2 with amounts ranging from $64 \mathrm{~g} \mathrm{~kg}^{-1}$ at week 1 to $56.5 \mathrm{~g} \mathrm{~kg}^{-1}$ at week 3, whereas in LeM_4C the sucrose amount increased from about $48 \mathrm{~g} \mathrm{~kg}^{-1}$ at week 1 to about $63 \mathrm{~g} \mathrm{~kg}^{-1}$ at week 2 and then decreased to about $51 \mathrm{~g} \mathrm{~kg}^{-1}$ with lengthening storage time. In contrast, sucrose amount was not significantly influenced by storage time in either MoM_0C or MoM_4C fruits. Fructose (about 18\% of total sugars) and sorbitol (about $4 \%$ of total sugars) significantly changed with storage time, the former decreasing from a value (mean \pm standard error) of $17.7 \pm 0.59 \mathrm{~g} \mathrm{~kg}^{-1}$ at harvest to about $14 \mathrm{~g} \mathrm{~kg}^{-1}$ at week 2 until the end of storage 

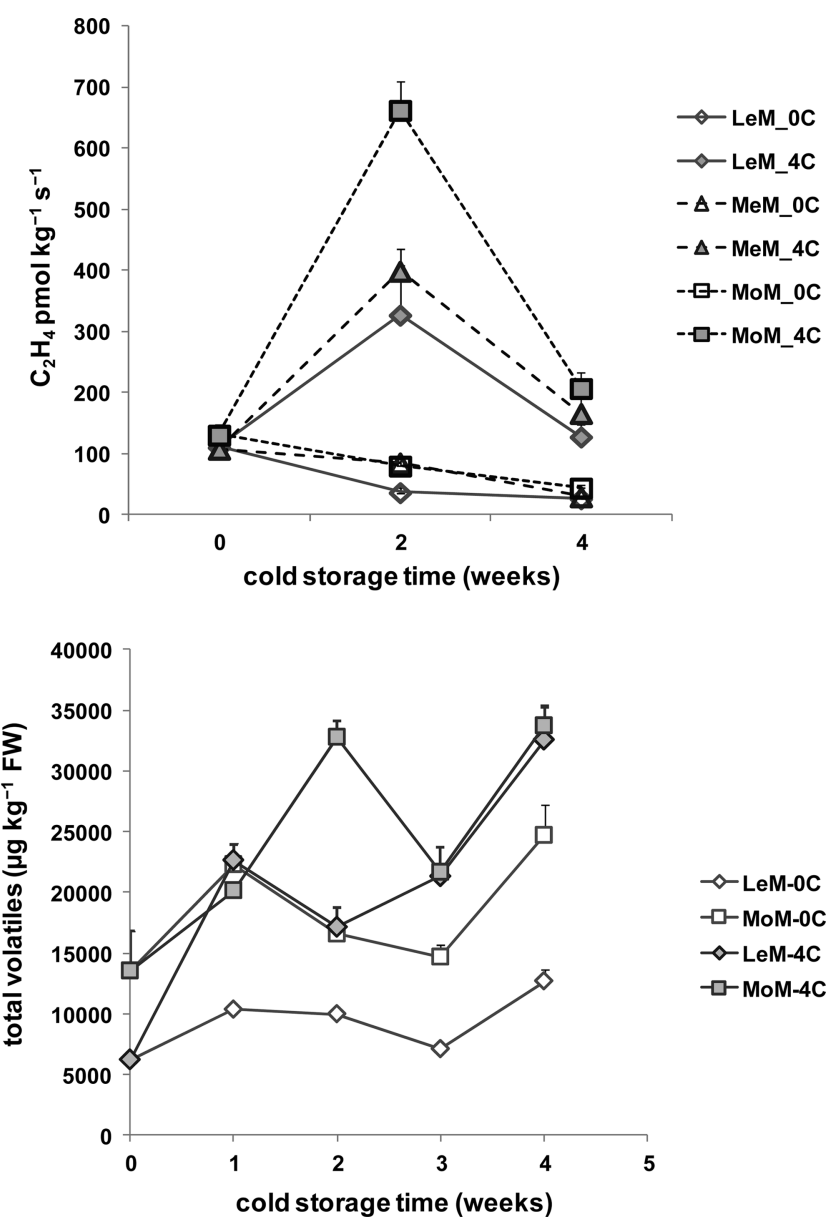

Figure 1. Ethylene production rate ( $\mathrm{pmol} \mathrm{kg} \mathrm{kg}^{-1} \mathrm{~s}^{-1}$, top) and total volatiles $\left(\mu \mathrm{g} \mathrm{kg}^{-1} \mathrm{FW}\right.$, bottom) of 'Spring Belle' peaches during 4 weeks of cold storage at 0 and $4{ }^{\circ} \mathrm{C}$. Maturity classes: LeM, less mature; MeM, medium mature; MoM, more mature. Bars refer to standard error of the mean.

and the latter showing a maximum value of $3.77 \pm 0.21 \mathrm{~g} \mathrm{~kg}^{-1}$ at week 1 and a minimum of $2.58 \pm 0.21 \mathrm{~g} \mathrm{~kg}^{-1}$ at week 4 . Glucose (17-21\% of total sugars) was strongly affected by TRS maturity class and storage temperature: it was higher in MoM fruit (mean value, $15.9 \pm 0.2 \mathrm{~g} \mathrm{~kg}^{-1}$ ) than in LeM fruit $\left(15 \pm 0.2 \mathrm{~g} \mathrm{~kg}^{-1}\right)$ and decreased from $20.2 \mathrm{~g} \mathrm{~kg}^{-1}$ at harvest to $16.8 \mathrm{~g} \mathrm{~kg}^{-1}$ after 1 week and further decreased to $14.0 \mathrm{~g} \mathrm{~kg}^{-1}$ from week 2 to the end of storage.

Malic acid was the main organic acid; it was higher at $0{ }^{\circ} \mathrm{C}$ than at $4{ }^{\circ} \mathrm{C}\left(0{ }^{\circ} \mathrm{C}, 7.99 \pm 0.09 \mathrm{~g} \mathrm{~kg}^{-1} ; 4{ }^{\circ} \mathrm{C}, 7.56 \pm 0.1 \mathrm{~g}\right.$ $\mathrm{kg}^{-1}$ ), in LeM than in MoM fruit (LeM, $8.38 \pm 0.09 \mathrm{~g} \mathrm{~kg}^{-1}$; MoM, $7.18 \pm 0.09 \mathrm{~g} \mathrm{~kg}^{-1}$ ) and decreased from $8.16 \pm 0.14 \mathrm{~g}$ $\mathrm{kg}^{-1}$ at harvest to $6.29 \pm 0.14 \mathrm{~g} \mathrm{~kg}^{-1}$ at week 4 of cold storage, amounts corresponding, respectively, to 54.2 and $47 \%$ of total acids. Citric acid, instead, did not significantly change with storage conditions, but it was higher in LeM fruit $(6.04 \pm 0.12$ $\mathrm{g} \mathrm{kg}^{-1}$; 36.6\% of total acids) than in MoM (4.56. $\pm 0.12 \mathrm{~g} \mathrm{~kg}^{-1}$; $33 \%$ of total acids). On the contrary, quinic acid increased with storage time from $1.87 \pm 0.04 \mathrm{~g} \mathrm{~kg}^{-1}$ at harvest $(12 \%$ of total acids) to $2.10 \pm 0.04 \mathrm{~g} \mathrm{~kg}^{-1}$ at week 1 (17\% of total acids) without any further significant change with lengthening storage time. As a consequence, the ratio $\mathrm{Su} / \mathrm{Ac}$ on average was lower at $0{ }^{\circ} \mathrm{C}(5.61 \pm 0.11)$ than at $4{ }^{\circ} \mathrm{C}(5.98 \pm 0.11)$, and in LeM $(5.26 \pm 0.11)$ than in MoM $(6.32 \pm 0.11)$ fruits, and significantly decreased from harvest $(6.27 \pm 0.18)$ to week 2 of
Table 3. Headspace Volatile Compounds Detected in 'Spring Belle' Peaches and Mode of Identification

\begin{tabular}{llllll}
\multicolumn{1}{c}{ compound } & \multicolumn{1}{c}{ code } & RI $^{a}$ & \multicolumn{2}{c}{ identification } \\
acetaldehyde & ALD & 380 & GC-MS & RI & St \\
ethanol & EtOL & 440 & GC-MS & RI & St \\
methyl acetate & MetAc & 531 & GC-MS & RI & St \\
unknown 1 & N.I. 1 & 545 & & & \\
unknown 2 & N.I. 2 & 560 & & & \\
unknown 3 & N.I. 3 & 575 & & & \\
ethyl acetate & EtAc & 600 & GC-MS & RI & St \\
2-propenyl acetate & PropAc & 673 & GC-MS & RI & \\
hexanal & HexAL & 778 & GC-MS & RI & St \\
(E)-2-hexenal & E2Hex & 825 & GC-MS & RI & St \\
(Z)-3-hexenol & HexOL & 838 & GC-MS & RI & St \\
$\quad$ + hexanol & & 838 & & & \\
benzaldehyde & Benz & 927 & GC-MS & RI & St \\
$(Z)$-3-hexenyl acetate & Z3HexAc & 981 & GC-MS & RI & St \\
hexyl acetate + (E)-2-hexenyl & HexAc & 998 & GC-MS & RI & St \\
$\quad$ acetate & & & & & \\
$\gamma$-hexalactone & $\gamma$-6 & 1006 & GC-MS & RI & St \\
$\gamma$-decalactone & $\gamma$-10 & 1429 & GC-MS & RI & St \\
$\gamma$-dodecalactone & $\gamma$-12 & 1668 & GC-MS & RI & St
\end{tabular}

${ }^{a} \mathrm{RI}$, retention index on $\mathrm{DB}-1$ column. ${ }^{b} \mathrm{GC}-\mathrm{MS}$, mass spectrum consistent with that of the NBS mass spectrum data base; St, comparison of retention data with those of authentic standard compounds; RI, retention index consistent with data from the literature.

storage $(5.16 \pm 0.18)$ and then increased to a value of $6.51 \pm$ 0.18 at the end of storage.

The decreasing trend with storage time for fructose, glucose, sorbitol, and malic acid found in this work is in agreement with the results obtained during maturation ${ }^{10,45,46}$ or cold storage $e^{10}$ of other peach cultivars. In addition, the lower values of $\mathrm{Su} / \mathrm{Ac}$ ratio and of glucose amount, coupled with the higher quantities of malic and citric acids found in LeM fruit, compared to MoM peaches, are consistent with the sugar and organic acid profiles of unripe fruit, ${ }^{46}$ confirming that the classification of fruit at harvest based on $\mu_{\mathrm{a}} 670$ actually allowed us to distinguish peach fruit with the distinctive "unripe" and "ripe" flavor patterns even after cold storage.

Sugar and acid composition data confirmed the good taste of 'Spring Belle' peaches: sugar amounts were in agreement with data on other peach cultivars, ${ }^{3,8}$ whereas the total organic acids amount of about $16 \mathrm{~g} \mathrm{~kg}^{-1}$, an unusual quantity for a ripe peach, confirms the typical high acidity of this cultivar. ${ }^{39}$

Ethylene Production Rate. At harvest, the EPR was on average about $117 \mathrm{pmol} \mathrm{kg}^{-1} \mathrm{~s}^{-1}$ (Figure 1, top) and was not different among the maturity classes. Instead, the variability of data decreased with increasing maturity, the standard errors being 27.2, 17.7, and 7.3 $\mathrm{pmol} \mathrm{kg}^{-1} \mathrm{~s}^{-1}$ for LeM, MeM, and MoM classes, respectively. With storage time, a different trend between temperatures was observed: at $0{ }^{\circ} \mathrm{C}$ there was a decrease in EPR with increasing storage time, whereas at $4{ }^{\circ} \mathrm{C}$ EPR peaked after 2 weeks of storage, independent of maturity class. Considering the maturity classes, LeM_0C fruit after 2 weeks produced less ethylene than MeM $0 \mathrm{C}^{-}$and MoM OC fruits, without changes with the increase of storage time. On the other hand, in MeM_0C and MoM_0C the EPR significantly decreased from 2 to 4 weeks of storage. At $4{ }^{\circ} \mathrm{C}$, LeM fruit produced less ethylene than MeM peaches after 2 weeks and less than MoM fruit after 2 and 4 weeks of storage. 


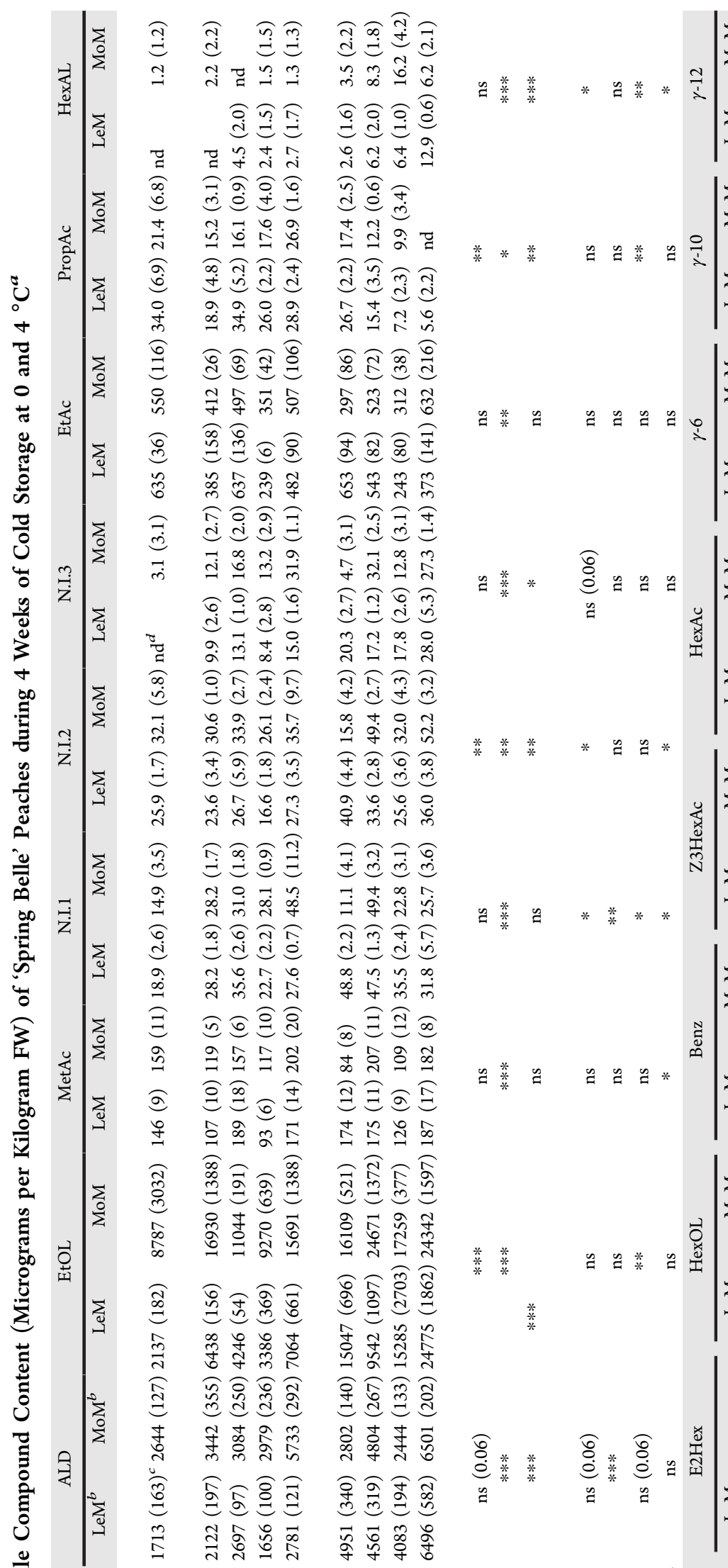

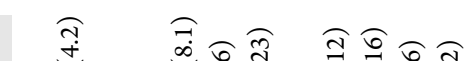

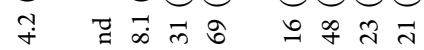

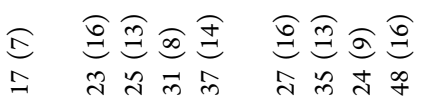

$\mathscr{*} *$

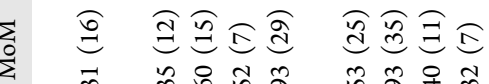

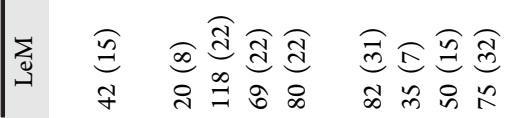

$g \mathscr{g}$

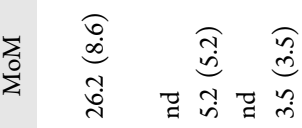

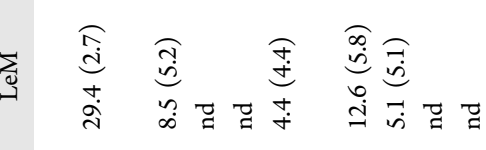

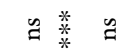

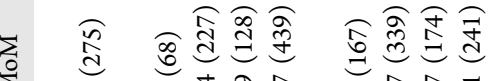

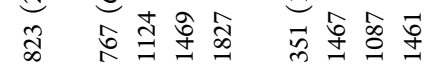

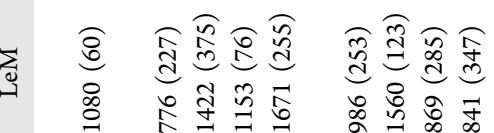

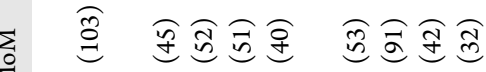

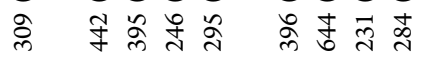

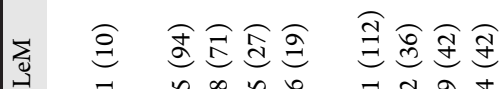

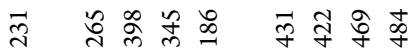

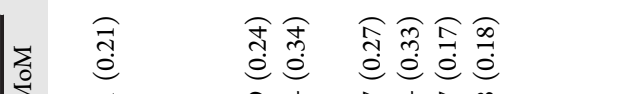

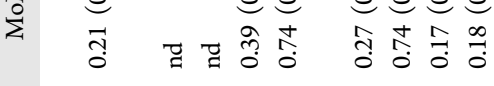

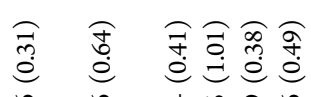

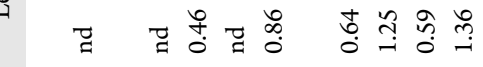

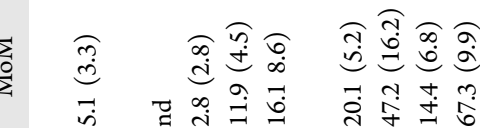

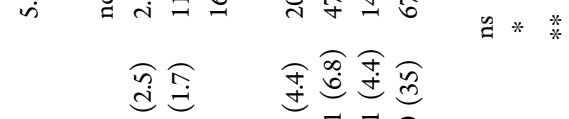

च चें

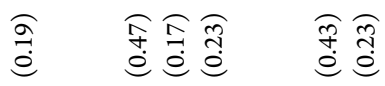

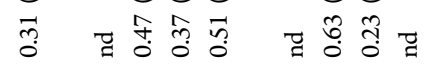

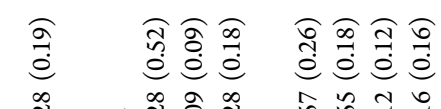

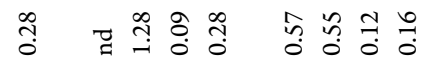




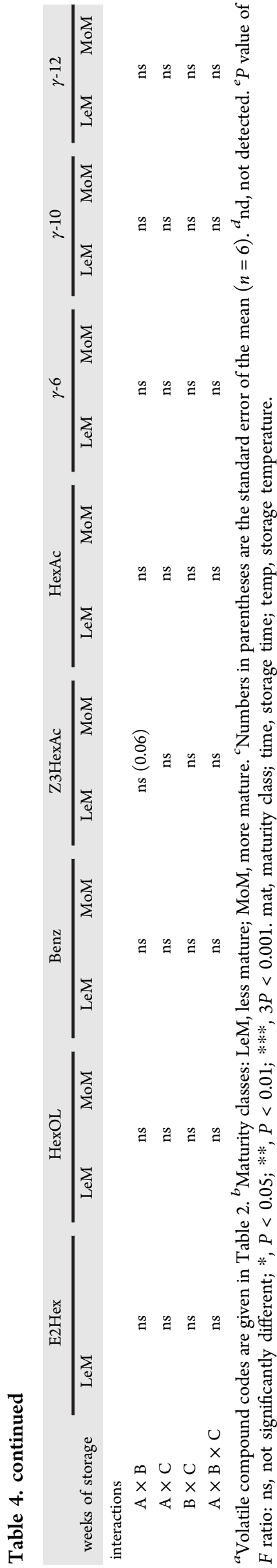

The different EPR trends according to both storage temperature and TRS maturity class are in agreement with the findings of Vanoli et al. ${ }^{27}$ on 'Spring Bright' nectarines sorted at harvest for maturity by $\mu_{\mathrm{a}} 670$ during a $250 \mathrm{~h}$ period of shelf life at 10 and $20^{\circ} \mathrm{C}$. The authors concluded that the different EPR curves of the different $\mu_{\mathrm{a}} 670$ classes could all be considered as normal climacteric curves with different time scales, from the longest (LeM stored at $10{ }^{\circ} \mathrm{C}$ ) to the shortest (MoM stored at $20{ }^{\circ} \mathrm{C}$ ). Notwithstanding that in our experiment fruits were stored at 0 and $4{ }^{\circ} \mathrm{C}$, which actually could slow the physiological processes of ripening, fruits stored at $4{ }^{\circ} \mathrm{C}$ showed a climacteric rise in EP at week 2 of storage, with a trend similar to that of the most mature class after $85 \mathrm{~h}$ at $20{ }^{\circ} \mathrm{C}$ reported by Vanoli et al. ${ }^{27}$ In addition, according to what was previously found in other peach cultivars, ${ }^{47}$ the climacteric peak in 'Spring Belle' peaches stored at $4{ }^{\circ} \mathrm{C}$ occurred when fruit had already softened (Figure 1, top; Table 1), with LeM, MeM, and MoM fruits showing at week 2 decreases in firmness with respect to harvest of about 48, 72, and 53\%, respectively.

Volatile Compounds. In the static headspace of 'Spring Belle' peaches, 19 volatile compounds were found at amounts greater than "trace" level in at least one sample (Table 3 ), with 16 identified by comparison of mass spectra, retention index, and authentic standard compounds. These compounds included 4 aldehydes, 3 alcohols, 6 esters, and 3 lactones. All of the volatile compounds quantified have been found in other peach cultivars; ${ }^{6}$ however, from the qualitative point of view, 'Spring Belle' peaches did not develop in detectable amounts terpenoids, responsible for the odor notes of the different cultivars. ${ }^{48}$ Compared to solvent extraction or vacuum steam distillation, with headspace sampling more esters and other "contributory" volatile compounds are obtained. ${ }^{48}$

Among the headspace techniques, the static sampling from just-thawed pulp purees was selected for this research to improve the sensitivity of the static-HS-GC method, as well as to have the same proportion between the volatile compounds as in the E-nose analysis, to distinguish which compounds are responsible for the sensor signal changes during cold storage. Modise $^{49}$ reported that in strawberry fruit freezing/thawing altered the volatile emission by increasing the abundance of esters, such as hexyl acetate, ethyl methyl hexanoate, methyl acetate, and aldehydes, mainly acetaldehyde. In addition, the effect of freezing/thawing depended on the treatments (freezing temperature and thawing conditions). On the other hand, Flores et al., ${ }^{50}$ in order to improve the sensitivity of SPME-GC/MS for the analysis of chiral volatile compounds in food matrices, suggested a sample freezing/defrosting prior to the HS-SPME extraction. The temperature of $70{ }^{\circ} \mathrm{C}$ used during the $30 \mathrm{~min}$ equilibration time prior to gas sampling, with respect to sampling without heating, could lead to an increase of the amounts of $\gamma$-decalactone and $\gamma$-dodecalactone, as shown by Derail et al., ${ }^{51}$ who reported an increase of flavor dilution factors for these lactones after a $2 \mathrm{~h}$ pulp cooking in an apparatus equipped for simultaneous steam distillation/ extraction, as well as the formation of new odorants that were not detected in a freshly prepared peach juice and that are not detected in our samples. Moreover, the same authors ${ }^{51}$ reported the degradation of (E)-2-hexanal, ( $Z$ )-3-hexenyl acetate, and $\gamma$-hexalactone, contributing to peach fresh odor, in the thermally treated peaches. As all of these compounds are detected in our samples, we could conclude that the $70{ }^{\circ} \mathrm{C}$ heating for $30 \mathrm{~min}$ is high enough to increase in some way the 

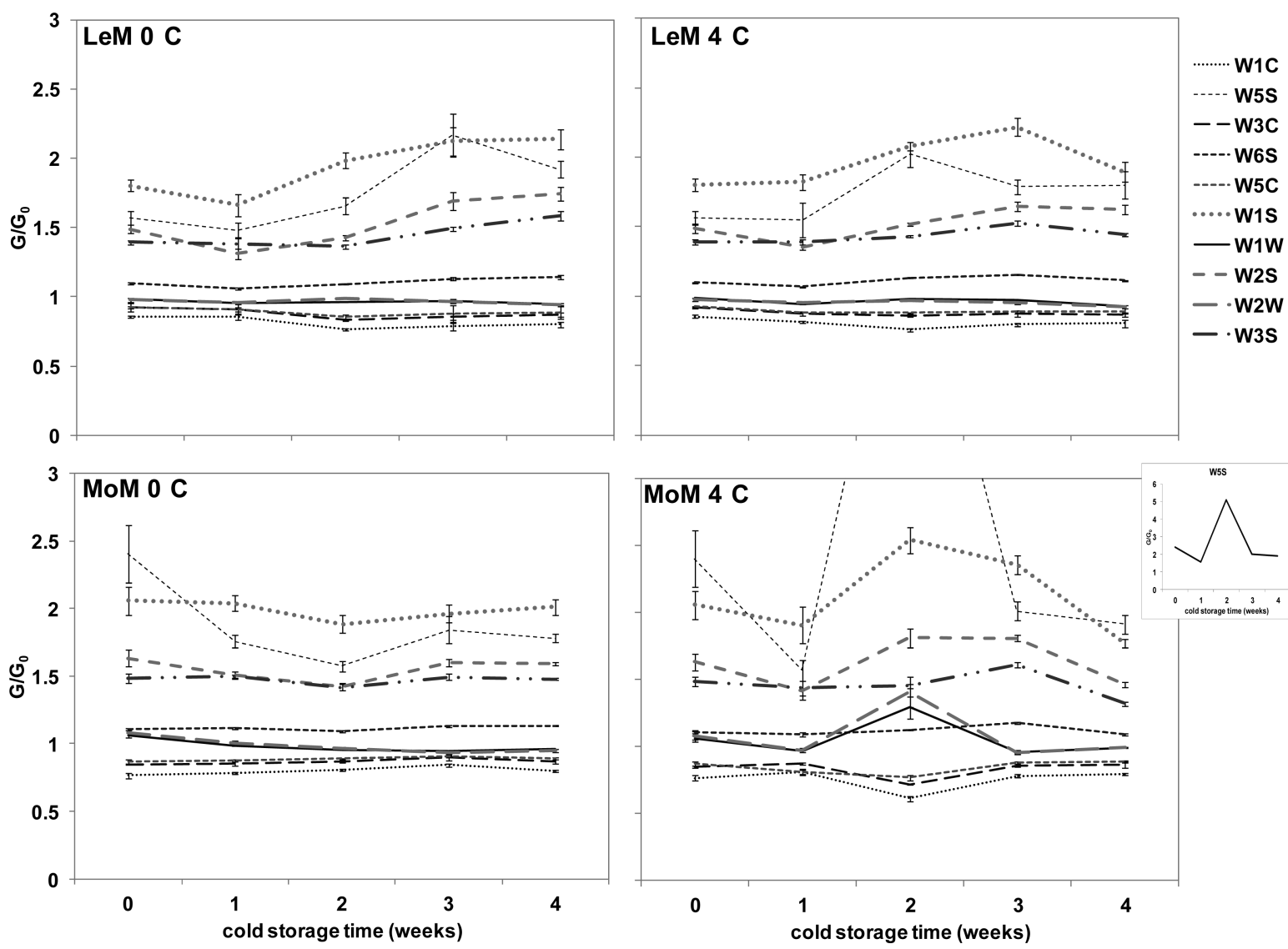

Figure 2. Relative conductivity $\left(G / G_{0}\right)$ of each sensor as a function of cold storage time at $0{ }^{\circ} \mathrm{C}$ (left) and $4{ }^{\circ} \mathrm{C}$ (right) in less (LeM) and more mature (MoM) 'Spring Belle' peaches. Bars refer to standard error of the mean.

concentration of lactones, but low enough to preserve the peach fresh odor contributing compounds.

The concentrations of volatile compounds at harvest and during cold storage at both temperatures for LeM and MoM 'Spring Belle' peaches are reported in Table 4. From a quantitative point of view, the most important volatiles were acetaldehyde, ethanol, methyl acetate, ethyl acetate, (Z)-3hexenyl acetate, and hexyl acetate $+(E)$-2-hexenyl acetate. At harvest (Figure 1, bottom), MoM fruit showed significantly higher total volatile compounds than LeM ones. With cold storage for both the maturity classes at both temperatures there was a significant increase in total volatiles after 1 week, followed by either a further increase at week 2 in MoM_4C or a steady state until week 2 in LeM_0C and until week 3 in LeM_4C and MoM_0C. At week 3, in LeM_0C and MoM_4C there was a decrease in total volatiles to values similar to those observed at harvest, followed by a significant increase in volatile production at the end of cold storage, reaching values of $\approx 12690 \mu \mathrm{g} \mathrm{kg}^{-1}$ in LeM_0C and $\approx 33700 \mu \mathrm{g} \mathrm{kg}^{-1}$ in MoM_4C. Also in MoM_0C and LeM_4C there was a significant increase in total volatiles at week 4, emitting the former at about $24700 \mu \mathrm{g} \mathrm{kg}^{-1}$ and the latter at about $33600 \mu \mathrm{g} \mathrm{kg}^{-1}$, amounts not different from that produced by MoM fruits stored at the same temperature. Also, Cano-Salazar et al. ${ }^{14}$ found an increase in total volatile emission with cold storage in the early-season cultivars 'Royal Glory' and 'Early Rich', showing a total volatile emission 1.5 times higher than at harvest after 40 and 20 days of storage at $-0.5{ }^{\circ} \mathrm{C}$, respectively.

Acetaldehyde on average accounted for $19 \%$ of total volatiles and was the main aldehyde found in the headspace (Table 4).
Acetaldehyde increased from an average of about $2180 \mu \mathrm{g} \mathrm{kg}^{-1}$ at harvest to about $3500 \mu \mathrm{g} \mathrm{kg}^{-1}$ after 2 weeks and $5320 \mu \mathrm{g}$ $\mathrm{kg}^{-1}$ at the end of storage; at $0{ }^{\circ} \mathrm{C}$ it was lower in LeM than in MoM fruits (LeM, $2210 \mu \mathrm{g} \mathrm{kg}^{-1}$; MoM, $3576 \mu \mathrm{g} \mathrm{kg}^{-1}$ ) and the opposite occurred at $4{ }^{\circ} \mathrm{C}$ ( $\mathrm{LeM}, 4315 \mu \mathrm{g} \mathrm{kg}^{-1}$; MoM, $3845 \mu \mathrm{g}$ $\left.\mathrm{kg}^{-1}\right)$. Ethanol was the main compound of headspace volatiles, making up from 55\% (harvest) to 68\% (4 weeks of storage) of total volatiles. It was 2 times higher in MoM fruit than in LeM, being on average $8900 \mu \mathrm{g} \mathrm{kg}^{-1}$ in LeM and $15300 \mu \mathrm{g} \mathrm{kg}^{-1}$ in MoM, and it followed a distinctive trend according to the storage temperature. At $0{ }^{\circ} \mathrm{C}$ there were two maxima of ethanol production with similar amounts at weeks 1 and 4 , whereas at $4{ }^{\circ} \mathrm{C}$ the highest ethanol production was reached after 2 and 4 weeks of storage for MoM fruit and at the end of storage for LeM ones. In previous studies carried out on 'Summerset' peaches, higher concentrations of ethanol and acetaldehyde with respect to those found in this research were found both at harvest and after 7,21 , and 35 days at $0{ }^{\circ} \mathrm{C}$ and 5 days at $20^{\circ} \mathrm{C}$, with a sharp increase in ethanol concentration after 1 week of storage, followed by a slight rise until the end of storage time, and an irregular trend throughout storage time for acetaldehyde. ${ }^{52}$ In addition, it was reported that acetaldehyde and ethanol levels in 'Rich May' and 'Ruby Rich' peaches increased with advancing maturation, and the increases in acetaldehyde and ethanol during maturation were associated with increases in other aroma volatiles. ${ }^{53}$

The aldehydes other than acetaldehyde were emitted in low amounts, from $\approx 0.3-0.4 \mu \mathrm{g} \mathrm{kg}^{-1}$ for $(E)$-2-hexenal and benzaldehyde to $\approx 4 \mu \mathrm{g} \mathrm{kg}^{-1}$ for hexanal. (E)-2-Hexenal did not significantly change with storage time in LeM_4C, MoM_4C, 

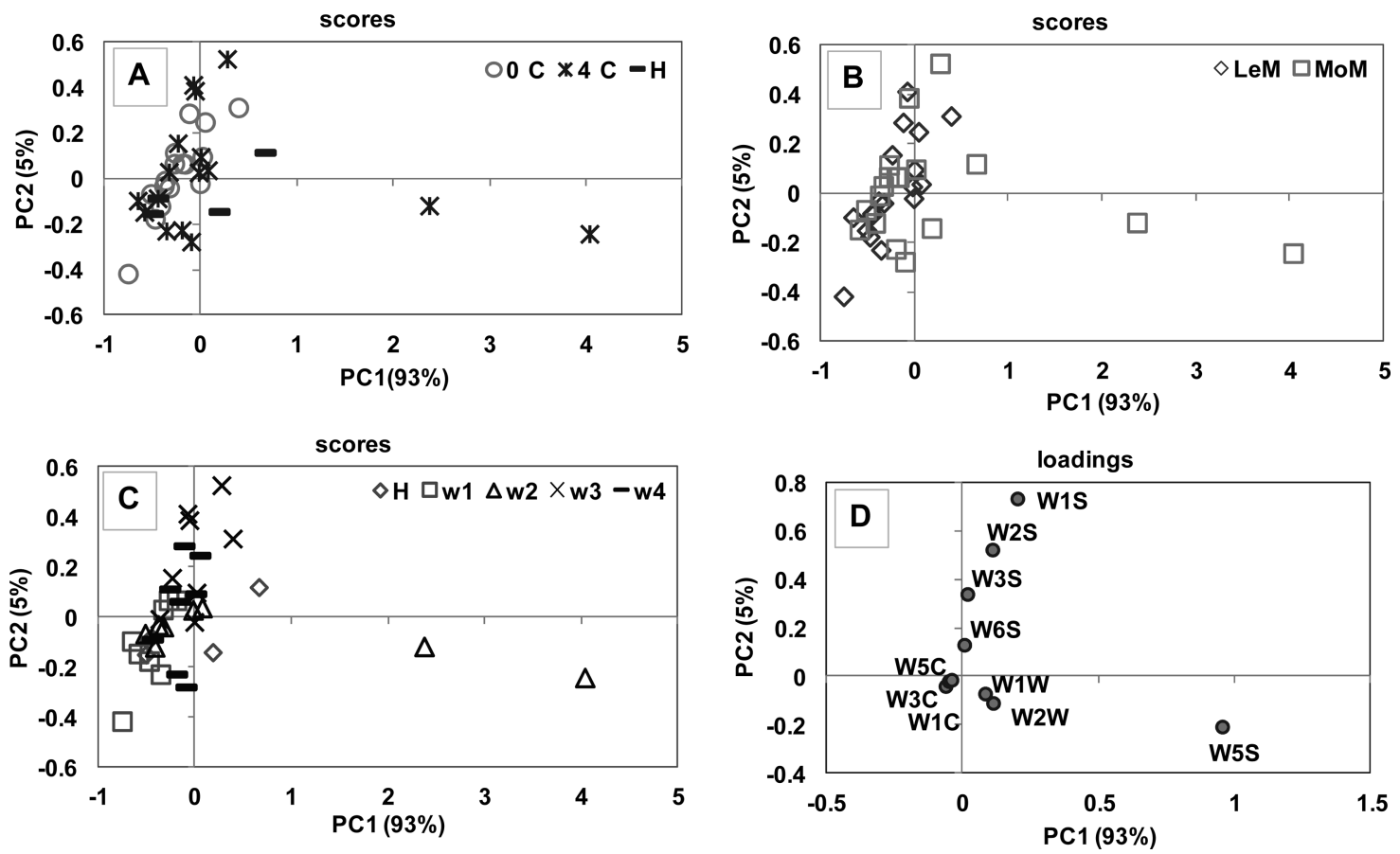

Figure 3. Scores and loadings plots of PC-1 versus PC-2 from PCA of electronic nose data.
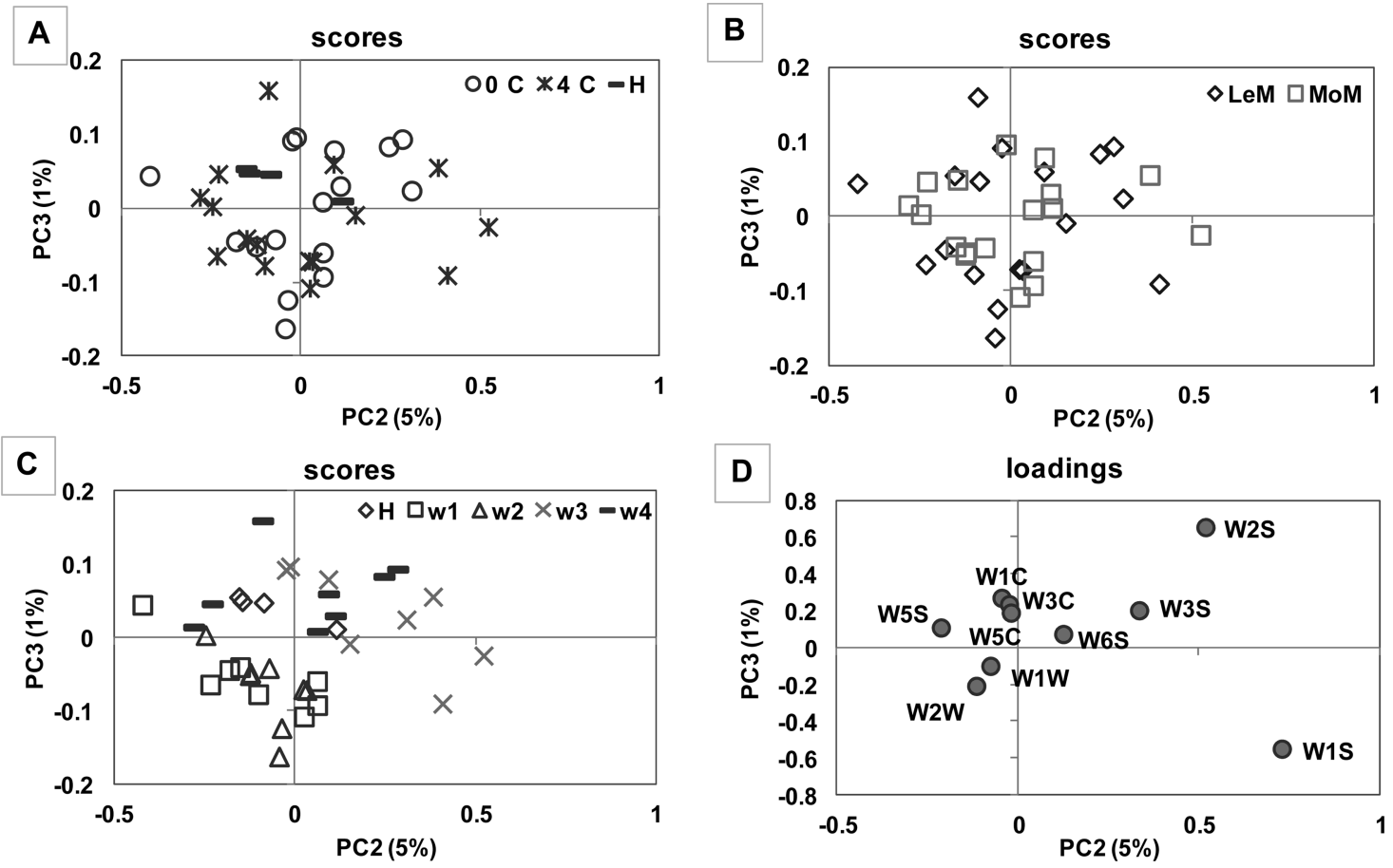

Figure 4. Scores and loadings plots of PC-2 versus PC-3 from PCA of electronic nose data.

and MoM_0C, whereas it peaked to $1.2 \mu \mathrm{g} \mathrm{kg}^{-1}$ at week 2 in LeM_0C. Hexanal significantly changed with storage time only at $4{ }^{\circ} \mathrm{C}$, showing a different trend according to maturity class: in LeM fruit it constantly increased from harvest to the end of storage, whereas in MoM peaches it peaked at week 3 . Benzaldehyde emission was not affected either by storage time and temperature or by maturity class. All of the aldehydes, with the exception of acetaldehyde, were emitted in amounts below their odor detection thresholds (hexanal, $2.4 \mu \mathrm{g} \mathrm{L}^{-1}{ }^{54}(E)-2$ hexenal, $110 \mu \mathrm{g} \mathrm{L}^{-1}$; $^{54}$ benzaldehyde, $350 \mu \mathrm{g} \mathrm{kg}^{-155}$ ) and, therefore, they would not contribute to 'Spring Belle' odor volatile pattern. On the contrary, acetaldehyde could actually contribute to the odor volatile pattern, being produced in amounts higher than its odor detection threshold of $25 \mu \mathrm{g} \mathrm{L}^{-1}$, imparting a fresh green note. ${ }^{54}$

The sum of the C-6 alcohols hexanol $+(Z)$-3-hexenol (HexOL) was not influenced by the maturity class; it was lower in peaches stored at $0{ }^{\circ} \mathrm{C}\left(\approx 4 \mu \mathrm{g} \mathrm{kg}^{-1}\right)$ than in those stored at $4{ }^{\circ} \mathrm{C}\left(\approx 28 \mu \mathrm{g} \mathrm{kg}^{-1}\right)$ and significantly increased from $2.5 \mu \mathrm{g} \mathrm{kg}^{-1}$ at harvest to $42 \mu \mathrm{g} \mathrm{kg}^{-1}$ at week 4 of storage. The concentration of 
HexOL was below the odor thresholds of both hexanol $(2500 \mu \mathrm{g}$ $\left.\mathrm{kg}^{-1}\right)^{55}$ and $(Z)-3$-hexenol $\left(3.9 \mu \mathrm{g} \mathrm{L}^{-1}\right),{ }^{54}$ and, hence, these C-6 alcohols actually could not contribute to the overall odor.

The six esters accounted for $12 \%$ of total volatiles (Table 4); hexyl acetate $+(E)$-2-hexenyl acetate (HexAc) and ethyl acetate were the main esters found in 'Spring Belle', and both were significantly influenced only by storage time: HexAc increased from an average of $952 \mu \mathrm{g} \mathrm{kg}^{-1}$ at harvest to $\approx 1300 \mu \mathrm{g} \mathrm{kg}^{-1}$ from week 2 to the end of storage, decreasing in proportion to total esters from harvest (48\%) to week 1 (42\%) and then increasing up to $60 \%$ at week 4 . In contrast, ethyl acetate decreased from a mean value of $592 \mu \mathrm{g} \mathrm{kg}^{-1}$ at harvest to $\approx 300 \mu \mathrm{g}$ $\mathrm{kg}^{-1}$ in storage, with a concomitant decrease in the proportion to total esters from $30 \%$ at harvest to $15 \%$ at week 3 . As for methyl acetate, accounting for 7\% of total esters, in MoM_4C there was a significant decrease from $\approx 150 \mu \mathrm{g} \mathrm{kg}^{-1}$ at harvest to $\approx 90 \mu \mathrm{g} \mathrm{kg}^{-1}$ at week 1 followed by a steep increase to $210 \mu \mathrm{g}$ $\mathrm{kg}^{-1}$ at week 2, whereas in LeM_0C, MoM_0C, and LeM_4C the methyl acetate amount did not change from harvest to week 2. Then, as storage time went on, in all samples there were a decrease to $90-120 \mu \mathrm{g} \mathrm{kg}^{-1}$ at week 3 and an increase to $150-$ $200 \mu \mathrm{g} \mathrm{kg}^{-1}$ at week 4 (Table 4). As for the two unsaturated esters, ( $Z$ )-3-hexenyl acetate was not influenced by maturity class; it was higher in fruit stored at $4{ }^{\circ} \mathrm{C}\left(\approx 390 \mu \mathrm{g} \mathrm{kg}^{-1}\right)$ than in fruit stored at $0{ }^{\circ} \mathrm{C}\left(\approx 312 \mu \mathrm{g} \mathrm{kg}^{-1}\right)$ and significantly increased from $270 \mu \mathrm{g} \mathrm{kg}^{-1}$ at harvest to $455 \mu \mathrm{g} \mathrm{kg}^{-1}$ at week 2, followed by a decrease to $311 \mu \mathrm{g} \mathrm{kg}^{-1}$ at week 4 . On the other hand, 2-propenyl acetate was higher in LeM class fruits $(23 \mu \mathrm{g}$ $\left.\mathrm{kg}^{-1}\right)$ than in MoM ones $\left(16 \mu \mathrm{g} \mathrm{kg}^{-1}\right)$; it did not significantly change during storage at $0{ }^{\circ} \mathrm{C}$, whereas at $4{ }^{\circ} \mathrm{C}$ it decreased from $28 \mu \mathrm{g} \mathrm{kg}^{-1}$ at harvest to $9 \mu \mathrm{g} \mathrm{kg}^{-1}$ after 3 weeks and to $2 \mu \mathrm{g} \mathrm{kg}^{-1}$ after 4 weeks of storage. It has been reported that high ester concentrations should give the peaches a pleasant flavor, as they are contributory volatile compounds imparting a fruity pleasant odor. ${ }^{14}$ Among the esters detected in the headspace of 'Spring Belle' peaches, ethyl acetate concentration was below its odor threshold of $5000 \mu \mathrm{g} \mathrm{kg}^{-1}, 55$ and, hence, it actually did not contribute to the overall odor. Instead, HexAc and (Z)-3-hexenyl acetate were present in concentrations above their odor thresholds (hexyl acetate and (E)-2-hexenyl acetate, $2 \mu \mathrm{g} \mathrm{kg}^{-1}$; 55 (Z)-3-hexenyl acetate, $\left.13 \mu \mathrm{g} \mathrm{L}^{-154}\right)$ in all of the samples, imparting a fruity, green odor note. $^{53}$

The three lactones found in this research were present in low proportions to total volatiles ( $0.6 \%$ to total volatiles; $3.9 \%$ to total volatiles other than ethanol and acetaldehyde), similarly to what was found by Cano-Salazar et al., ${ }^{14}$ Wang et al., ${ }^{6}$ and Ortiz et al., ${ }^{12}$ who used a headspace technique as volatile sampling method. $\gamma$-Hexalactone accounted for $36 \%$ of total lactones at harvest, and it steeply decreased from a mean value of $28 \mu \mathrm{g}$ $\mathrm{kg}^{-1}$ at harvest to $5 \mu \mathrm{g} \mathrm{kg}^{-1}$ at week 1 and then further decreased to very low amounts at the end of storage, accounting for only $1.7 \%$ of total lactones. In addition, in MoM_4C $\gamma$-hexalactone was not detected during the whole storage time. A decreasing level of $\gamma$-hexalactone just after 1 week of storage at $1{ }^{\circ} \mathrm{C}$ has been reported for 'Spring Lady' and 'Regina Bianca' peaches. ${ }^{11} \gamma$-Dodecalactone significantly increased with storage time, reaching $43 \mu \mathrm{g} \mathrm{kg}^{-1}$ at week 4 , which is an increase from $15 \%$ at harvest to $38 \%$ at the end of storage on the basis of total lactone production. In contrast, $\gamma$-decalactone content was not significantly influenced either by storage conditions (time and temperature) or by maturity class, but its proportion to total lactones increased from $49 \%$ at harvest to $71 \%$ at week 2 , and then it slightly decreased to $60 \%$ at the end of storage. These

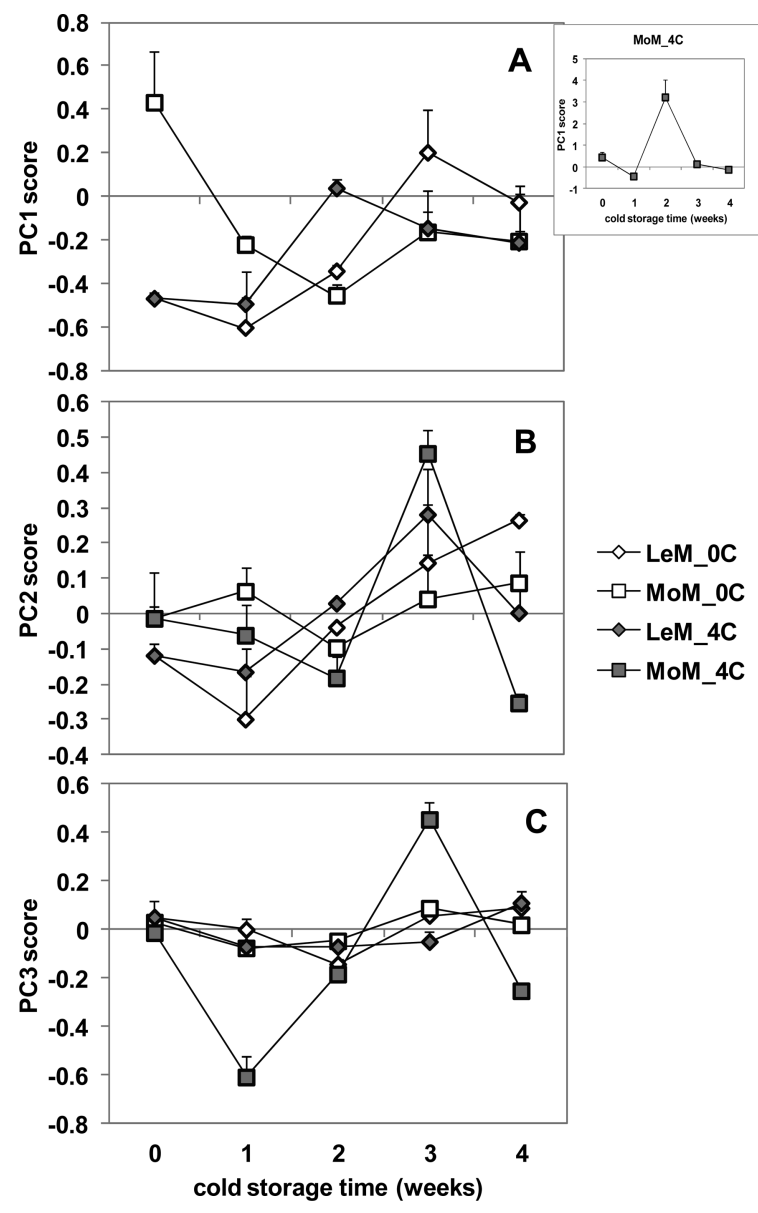

Figure 5. PC-1, PC-2, and PC-3 score trends as a function of cold storage time at 0 and $4{ }^{\circ} \mathrm{C}$ for less (LeM) and more (MoM) mature 'Spring Belle' peaches. Bars refer to standard error of the mean.

changes in the lactone pattern are important considering that, among peach volatiles, $\gamma$-decalactone and $\gamma$-dodecalactone are characterized by relatively low odor detection thresholds (1.1 and $0.43 \mu \mathrm{g} \mathrm{L}^{-1}$, respectively ${ }^{54}$ ) and are recognized as the "character impact" compounds of peach aroma, imparting the lactone-like, peach-like odor notes. ${ }^{54}$ An increasing trend in concentration for the long side-chain lactones $(\gamma-10$ and $\gamma$-12) during cold storage has also been reported in other peach cultivars $^{10,11}$ and was ascribed to the last period of the maturation process, which is characterized in peaches by highly active lactone metabolism. ${ }^{11}$

Electronic Nose Sensor Response Data. The evolution of the signals generated by the sensor array as a function of cold storage time and temperature for LeM and MoM peaches is shown in Figure 2. Each line represents the average signal variation of replicated samples for one sensor of the array, linking the conductance increase or decrease experienced by the sensors to the evolution of maturity over storage time according to both TRS maturity class and storage temperature. The responses of the 10 MOS sensors significantly changed with storage time in all samples, with the exception of $\mathrm{W} 2 \mathrm{~W}$ in LeM $0 \mathrm{C}$ and W1S and W3S in MoM 0C. Sensor responses significantly depended on fruit maturity: some sensors had higher responses in fruit characterized by a less advanced maturation degree, that is, either LeM fruits (W1C, W3C, and W5C) or fruits stored at $0{ }^{\circ} \mathrm{C}(\mathrm{W} 1 \mathrm{C}$ and $\mathrm{W} 3 \mathrm{C})$ or fruits at harvest or with a short period of cold storage (W1C, W3C, and 


\section{PC-1}

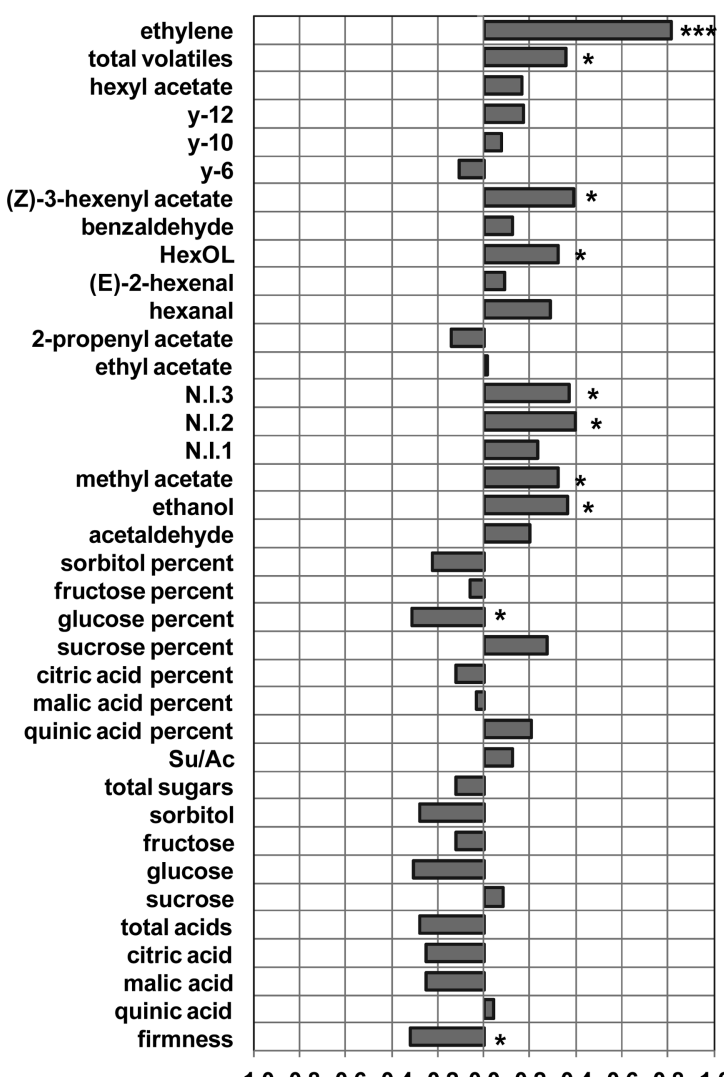

PC-2

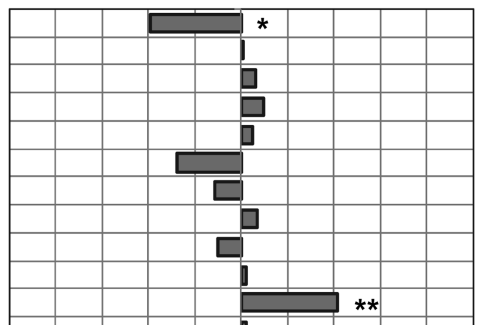

PC-3

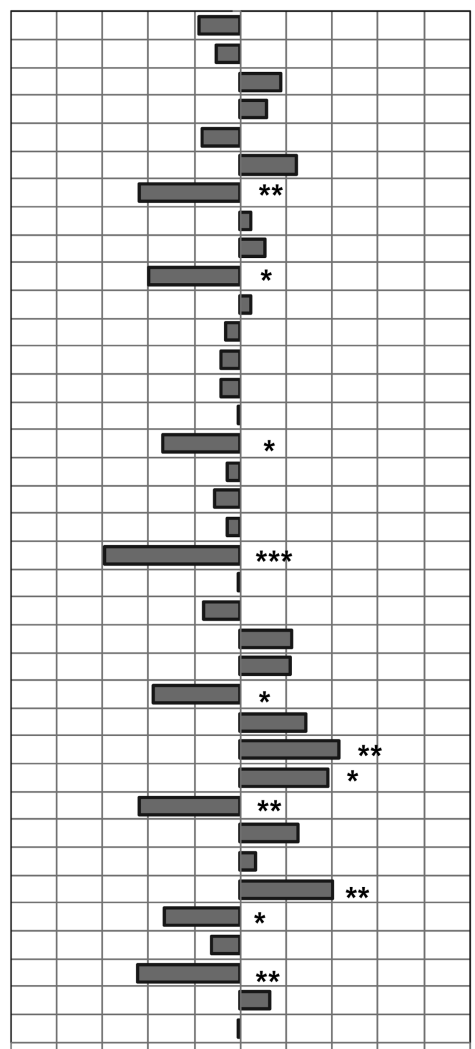

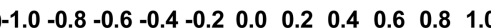

Figure 6. Linear correlation coefficients of PC-1, PC-2, and PC-3 with firmness, flavor, and volatile components (significance of $r$ : *, $P \leq 0.05 ; * *, P \leq 0.01$; and ***, $P \leq 0.001)$.

W5C), whereas the sensors W5S, W1W, and W2W showed higher responses in fruit having a more advanced maturation degree (MoM peaches, or stored at $4{ }^{\circ} \mathrm{C}$, or at the end of cold storage). These results agree with Brezmes et al., ${ }^{36}$ who found increased conductivity values of the W5S sensor during postharvest ripening of peaches and pears.

To see whether the sensor array was able to distinguish between different storage conditions and different maturities, PCA was applied to the E-nose measurements of the 40 peach samples. The first three principal components explained together $99 \%$ of the total variance, but almost all of the variance was on PC-1 (93\% of explained variance). The score plots of PC-1 versus PC-2 (Figure 3 ) and of PC-2 versus PC-3 (Figure 4) show the separation of the 40 peach samples according to the storage temperature compared to sample at harvest (panel A), the maturity class (panel B), and the time of cold storage (panel $C$ ). Fruits were distributed along PC-1 from right to left (Figure 3), with more mature peaches having higher scores. In fact, negative PC-1 scores were found for fruit belonging to LeM class either at harvest or after 1 week of storage at $0{ }^{\circ} \mathrm{C}$; in contrast, the highest $\mathrm{PC}-1$ scores were found for fruit belonging to the MoM class after 2 weeks of storage at $4{ }^{\circ} \mathrm{C}$, which showed the rise in ethylene production coupled with the highest total volatile production and sugar and acid composition proper of ripe peach fruits. An increase of PC-1 scores with storage time was also observed in LeM_0C and LeM 4C samples, the former having the highest score at week 3 and the latter at week 2 (Figure 5A). Furthermore, the scores plot reported in Figure 4C shows that PC-2 (5\% of explained variance) opposed the majority of fruit samples belonging to harvest time and 1 and 2 weeks of storage, which were characterized by negative PC- 2 scores, to those stored for the longer periods, with peaches stored for 3 weeks at $4{ }^{\circ} \mathrm{C}$ having the higher scores. Along the PC-3 axis ( $1 \%$ of explained variance), instead, peaches after 1 and 2 weeks of storage are opposed to fruit at harvest and after 3 and 4 weeks of storage. In fact, the scores of PC-2 and PC-3 significantly changed with storage time and in different ways according to storage temperature and maturity class (Figure 5B,C). In LeM_0C fruit, PC-2 scores increased with storage time with the highest value observed at week 4 , and PC-3 scores significantly decreased from harvest to week 2 and then increased up to 4 week, reaching values similar to those found at harvest. In MoM_0C, PC-2 scores did not change with storage time, whereas PC-3 showed the lowest value at week 2 and the highest at harvest and after 3 weeks of storage. LeM_4C was characterized by high PC-2 scores at week 3 and lower PC-3 scores at weeks 1 and 2, whereas in MoM_4C both PC-2 and PC-3 showed the highest score at week 3 of storage.

Considering the loading plots showing the relationship between the electronic nose variables (Figures 3D and 4D), the W5S, W1S, and W2S sensors had the highest influence on the pattern, W5S being the most relevant in PC-1, W1S in PC-2, and $\mathrm{W} 2 \mathrm{~S}$ in $\mathrm{PC}-3$. These results confirm those reported by Benedetti et al., ${ }^{34}$ who found for four peach cultivars that a subset of a few PEN2 sensors (W5S, W2S, and W1S) can be chosen to explain almost all of the variance, emphasizing that 
only the W5S sensor was relevant in the discrimination of peaches into unripe, ripe, and over-ripe categories.

Correlations between Sensor Pattern and Flavor Components and Volatile Compounds. To compare the E-nose sensor responses with composition data, the correlation between PC-1, PC-2, and PC-3 with ethylene, volatile compounds, organic acid and sugar compositions, and firmness has been considered (Figure 6). The highest correlation was found between PC-1 and ethylene production; PC-1 was positively correlated also with total volatiles, (Z)-3-hexenyl acetate, HexOL, N.I.1, N.I.2, methyl acetate, and ethanol, even if with low $r$ values, and negatively correlated with percent glucose and firmness, both decreasing with increasing fruit ripening. In PC-1 the variable with the highest weight is the W5S sensor (see Figure 3D), and this sensor is reported to be highly related to unsaturated volatile compounds and, hence, to ethylene and the other unsaturated volatile compounds detected. This relationship was also found by Benedetti et al. ${ }^{34}$ and Brezmes et al. $^{36}$ for other peach cultivars. PC-2, instead, showed higher $r$ with hexanal (positive) and ethyl acetate (negative), along with significant correlations with percent sucrose (positive), glucose, sorbitol, percent glucose, and ethylene (negative). PC-3 was mainly related to flavor components, showing correlations with percent sorbitol, percent malic acid, total acids, sorbitol, malic acid (negative), total sugars, sucrose, and $\mathrm{Su} / \mathrm{Ac}$ ratio (positive). Moreover, PC3 was negatively correlated with $(Z)$-3-hexenyl acetate, $(E)-2$ hexenal, and N.I.1.

To summarize, all of the quality characteristics studied in this work differed according to the ripening degree of fruit achieved either by the classification in maturity classes according to $\mu_{\mathrm{a}} 670$ or by storage conditions (time and/or temperature). The volatile profile, that is, the odor quality, was in agreement with ripening stage and storage conditions, and some volatile compounds, mainly the unsaturated ones, were correlated with selected sensors. Our results suggest that coupling the nondestructive measurement of maturity by means of the TRS optical technique with the E-nose technology could be a useful tool for the quality management of peach fruit in storage.

\section{AUTHOR INFORMATION}

\section{Corresponding Author}

*Phone: +39-02-23.95.57.213. Fax.: +39-02-23.65.377. E-mail: anna.rizzolo@entecra.it.

\section{Funding}

We are grateful for Grant Agreement 228334 Laserlab-Europe II (EU FP7-Infrastructures-2008-1) for a fellowship to S.L.

\section{Notes}

The authors declare no competing financial interest.

\section{ACKNOWLEDGMENTS}

We thank the Cooperativa Intesa, Faenza (Ravenna Province), for supplying peaches.

\section{REFERENCES}

(1) Giovannoni, J. J. Genetic regulation of fruit development and ripening. Plant Cell 2004, 16, S170-S180.

(2) Camejo, D.; Martí, M. C.; Román, P.; Ortiz, A.; Jiménez, A. Antioxidant system and protein pattern in peach fruits at two maturation stages. J. Agric. Food Chem. 2010, 58, 11140-11147.

(3) Colaric, M.; Veberic, R.; Stampar, F.; Hudina, M. Evaluation of peach and nectarine fruit quality and correlations between sensory and chemical attributes. J. Sci. Food Agric. 2005, 85, 2611-2616.
(4) Ortiz, A.; Echeverría, G.; Graell, J.; Lara, I. Overall quality of 'Rich Lady' peach fruit after air- or CA storage. The importance of volatile emission. LWT-Food Sci. Technol. 2009, 42, 1520-1529.

(5) Aubert, C.; Ambid, C.; Baumes, R.; Gunata, Z. Investigation of bound aroma constituents of yellow-fleshed nectarines (Prunus persica L. cv. Springbright). Changes in bound aroma profile during maturation. J. Agric. Food Chem. 2003, 51, 6280-6286.

(6) Wang, Y.; Yang, C.; Li, S.; Yang, L.; Wang, Y.; Zhao, J.; Jiang, Q. Volatile characteristics of 50 peaches and nectarines evaluated by HPSPME with GC-MS. Food Chem. 2009, 116, 356-364.

(7) Lavilla, T.; Recasens, I.; Lopez, M. L.; Puy, J. Multivariate analysis of maturity stages, including quality and aroma, in 'Royal Glory' peaches and 'Big Top' nectarines. J. Agric. Food Chem. 2002, 82, 18421849.

(8) Borsani, J.; Budde, C. O.; Porrini, L.; Lauxmann, M. A.; Lombardo, V. A.; Murray, R.; Andreo, C. S.; Drincovich, M. F.; Lara, M. V. Carbon metabolism of peach fruit after harvest: changes in enzymes involved in organic acid and sugar level modifications. J. Exp. Bot. 2009, 60, 1823-1837.

(9) Lombardo, V. A.; Osorio, S.; Borsani, J.; Lauxmann, A.; Bustamante, C. A.; Budde, C. O.; Andreo, C. S.; Lara, M. V.; Fernie, A. R.; Drincovich, M. F. Metabolic profiling during peach fruit development and ripening reveals the metabolic networks that underpin each developmental stage. Plant Physiol. 2011, 57, 16961710.

(10) Vanoli, M.; Visai, C; Rizzolo, A. Peach quality: influence of ripening and cold storage. Acta Hortic. 1995, 379, 445-450.

(11) Raffo, A.; Nardo, N.; Tabilio, M. R.; Paoletti, F. Effects of cold storage on aroma compounds of white- and yellow-fleshed peaches. Eur. Food Res. Technol. 2008, 226, 1503-1512.

(12) Ortiz, A.; Graell, J.; López, M. L.; Echeverría, G.; Lara, I. Volatile ester-synthesising capacity in 'Tardinelle' peach fruit in response to controlled atmosphere and 1-MCP treatment. Food Chem. 2010, 123, 698-704.

(13) Zhang, B.; Xi, W. P.; Wei, W. W.; Shen, J. Y.; Ferguson, I.; Chen, K. S. Changes in aroma-related volatiles and gene expression during low temperature storage and subsequent shelf-life of peach fruit. Postharvest Biol. Technol. 2011, 60, 7-16.

(14) Cano-Salazar, J.; Echeverría, G.; Crisosto, C. H.; Lopez, L. Coldstorage potential of four yellow-fleshed peach cultivars defined by their volatile compounds emissions, standard quality parameters, and consumer acceptance. J. Agric. Food Chem. 2012, 60, 1266-1282.

(15) Etienne, C.; Moing, A.; Dirlewanger, E.; Raymond, P.; Monet, $\mathrm{R}$; Rothan, C. Isolation and characterization of six peach cDNAs encoding key proteins in organic acid metabolism and solute accumulation: involvement in regulating peach fruit acidity. Physiol. Plant. 2002, 114, 259-270.

(16) Crisosto, H. C. How do we increase peach consumption? Acta Hortic. 2002, 592, 601-605.

(17) Iglesias, I.; Echeverria, G. Differential effect of cultivar and harvest date on nectarine colour, quality and consumer acceptance. Sci. Hortic. 2009, 120, 41-50.

(18) Herrero-Langreo, A.; Fernández-Ahumada, E.; Roger, J. M.; Palagós, B.; Lleó, L. Combination of optical and non-destructive techniques for the measurement of maturity in peach. J. Food Eng. 2012, 108, 150-157.

(19) Cubeddu, R.; D’Andrea, C.; Pifferi, A.; Taroni, P.; Torricelli, A.; Valentini, G.; Dover, C.; Johnson, D.; Ruiz-Altisent, M.; Valero, C. Nondestructive quantification of chemical and physical properties of fruits by time-resolved reflectance spectroscopy in the wavelength range 650-1000 nm. Appl. Opt. 2001, 40, 538-453.

(20) Torricelli, A.; Spinelli, L.; Contini, D.; Vanoli, M.; Rizzolo, A.; Eccher Zerbini, P. Time-resolved reflectance spectroscopy for nondestructive assessment of food quality. Sensing Instrum. Food Qual. Saf. 2008, 2, 82-89.

(21) Cubeddu, R.; D’Andrea, C.; Pifferi, A.; Taroni, P.; Torricelli, A.; Valentini, G.; Ruiz-Altisent, M.; Valero, C.; Ortiz, C.; Dover, C.; Johnson, D. Time-resolved reflectance spectroscopy applied to the 
non-destructive monitoring of the internal optical properties in apples. Appl. Spectrosc. 2001, 55, 1368-1374.

(22) Tijskens, L. M. M.; Eccher Zerbini, P.; Shouten, R. E.; Vanoli, M.; Jacob, S.; Grassi, M.; Cubeddu, R.; Spinelli, L.; Torricelli, A. Assessing harvest maturity in nectarines. Postharvest Biol. Technol. 2007, 45, 204-213.

(23) Eccher Zerbini, P.; Vanoli, M.; Lovati, F.; Spinelli, L.; Torricelli, A.; Rizzolo, A.; Lurie, S. Maturity assessment at harvest and prediction of softening in a late maturing nectarine cultivar after cold storage. Postharvest Biol. Technol. 2011, 62, 275-281.

(24) Eccher Zerbini, P.; Vanoli, M.; Grassi, M.; Rizzolo, A.; Fibiani, M.; Cubeddu, R.; Pifferi, A.; Spinelli, L.; Torricelli, A. A model for the softening of nectarines based on sorting fruit at harvest by timeresolved reflectance spectroscopy. Postharvest Biol. Technol. 2006, 39, 223-232.

(25) Eccher Zerbini, P.; Vanoli, M.; Rizzolo, A.; Jacob, S.; Torricelli, A.; Spinelli, L.; Schouten, R. E. Time-resolved reflectance spectroscopy as a management tool in the fruit supply chain: an export trial with nectarines. Biosyst. Eng. 2009, 102, 360-363.

(26) Jacob, S.; Vanoli, M.; Grassi, M.; Rizzolo, A.; Eccher Zerbini, P.; Cubeddu, R.; Pifferi, A.; Spinelli, L.; Torricelli, A. Changes in sugar and acid composition of 'Ambra' nectarines during shelf life based on non-destructive assessment of maturity by time-resolved reflectance spectroscopy. J. Fruit Ornam. Plant Res. 2006, 14, 183-194.

(27) Vanoli, M.; Eccher Zerbini, P.; Grassi, M.; Jacob, S.; Rizzolo, A.; Torricelli, A.; Spinelli, L.; Cubeddu, R. Ethylene production in nectarine fruit of different maturity as measured by time-resolved reflectance spectroscopy. In Advances in Plant Ethylene Research; Ramina, A., et al., Eds.; Springer: Dordrecht, The Netherlands, 2007; pp 219-221.

(28) Vanoli, M.; Jacob, S.; Spinelli, L.; Torricelli, A.; Eccher Zerbini, P.; Rizzolo, A. Time-resolved reflectance spectroscopy as a tool for selecting at harvest 'Ambra' nectarines for aroma quality. Acta Hortic. 2008, 796, 231-235.

(29) Lurie, S.; Crisosto, C. H. Chilling injury in peach and nectarines. Postharvest Biol. Technol. 2005, 37, 195-208.

(30) Lurie, S.; Vanoli, M.; Dagar, A.; Weksler, A.; Lovati, F.; Eccher Zerbini, P.; Spinelli, L.; Torricelli, A.; Feng, J.; Rizzolo, A. Chilling injury in stored nectarines and its detection by time-resolved reflectance spectroscopy. Postharvest Biol. Technol. 2011, 59, 211-218.

(31) Peris, M.; Escuder-Gilabert, L. A 21st century technique for food control: electronic noses. Anal. Chim. Acta 2009, 638, 1-15.

(32) Baldwin, A. E.; Bai, J.; Plotto, A.; Dea, S. Electronic noses and tangues: applications for the food and pharmaceutical industries. Sensors 2011, 11, 4744-4766.

(33) Ghasemi-Varnamkhasti, M.; Mohtasebi, S. S.; Siadat, M. Biomimetic-based odor and taste sensing systems to food quality and safety characterization: an overview on basic principles and recent achievements. J. Food Eng. 2010, 100, 377-387.

(34) Benedetti, S.; Buratti, S.; Spinardi, A.; Mannino, S.; Mignani, I. Electronic nose as a non-destructive tool to characterise peach cultivars and to monitor their ripening stage during shelf-life. Postharvest Biol. Technol. 2008, 47, 181-188.

(35) Infante, R.; Farcuh, M.; Menenes, C. Monitoring the sensorial quality and aroma through an electronic nose in peaches during storage. J. Sci. Food Agric. 2008, 88, 2073-2078.

(36) Brezmes, J.; Llobet, E.; Vilanova, X.; Saiz, G.; Correig, X. Fruit ripeness monitoring using electronic nose. Sens. Actuators B 2000, 69, 223-229.

(37) Di Natale, C.; Zude-Sasse, M.; Macagnano, A.; Paolesse, R.; Herold, B.; D'Amico, A. Outer product analysis of electronic nose and visible spectra: application to the measurement of peach fruit characteristics. Anal. Chim. Acta 2002, 459, 107-117.

(38) Zhang, H.; Chang, M.; Wang, J.; Ye, S. Evaluation of peach quality indices using electronic nose by MLR, QPST and BP network. Sens. Actuators B 2008, 134, 332-338.

(39) Di Vaio, C.; Graziani, G.; Marra, L.; Cascone, A.; Ritieni, A. Antioxidant capacities, carotenoids and polyphenols evaluation of fresh and refrigerated peach and nectarine cultivars from Italy. Eur. Food Res. Technol. 2008, 227, 1225-1231.

(40) Lill, R. E.; van der Mespel, G. J. A method for measuring the juice content of mealy nectarines. Sci. Hortic. 1988, 36, 267-271.

(41) Rizzolo, A.; Visai, C. Metodo per il dosaggio del 2,5norbornadiene e dell'etilene in atmosfere a volumi costanti. Ann. I. V. T. P. A. 1985, 16, 17-24.

(42) Rizzolo, A.; Polesello, A.; Polesello, S. Use of headspace capillary GC to study the development of volatile compounds in fresh fruits. J. High Resolut. Chromatogr. 1992, 15, 472-477.

(43) Forni, E.; Erba, M. L.; Maestrelli, A.; Polesello, A. Sorbitol and free sugar contents in plums. Food Chem. 1992, 44, 269-275.

(44) Dagar, A.; Weksler, A.; Friedman, H.; Ogundiwin, E. A.; Crisosto, C. H.; Ahmad, R.; Lurie, S. Comparing ripening and storage characteristics of 'Oded' peach and its nectarine mutant 'Yuval'. Postharvest Biol. Technol. 2011, 60, 1-6.

(45) Chapman, G. W., Jr.; Horvat, R. J. Changes of nonvolatile acids, sugars, pectin, and sugar composition of pectins during peach (cv Monroe) maturation. J. Agric. Food Chem. 1990, 38, 383-387.

(46) Liverani, A.; Cangini, A. Ethylene evolution and changes in carbohydrates and organic acid during maturation of two white and two yellow fleshed peach cultivars. Adv. Hortic. Sci. 1991, 5, 59-63.

(47) Tonutti, P.; Bonghi, C.; Ramina, A. Fruit firmness and ethylene biosynthesis in three cultivars of peach (Prunus persica L. Batsch). J. Hortic. Sci. 1996, 71, 141-147.

(48) Rizzolo, A.; Lombardi, P.; Vanoli, M.; Polesello, S. Use of capillary gas chromatography/sensory analysis as an additional tool for sampling technique comparison in peach aroma analysis. J. High Resolut. Chromatogr. 1995, 18, 309-314.

(49) Modise, D. M. Does freezing and thawing affect the volatile profiles of strawberry fruit (Fragaria $\times$ ananassa Duch.)? Postharvest Biol. Technol. 2008, 50, 25-30.

(50) Flores, G.; Ruiz del Castillo, M. L.; Blanch, G. P.; Herraiz, M. Effect of sample freezing on the SPME performance in the analysis of chiral volatile compounds in foods. Food Chem. 2006, 96, 334-339.

(51) Derail, C.; Hofmann, T.; Schieberle, P. Differences in key odorants of handmade juice of yellow-flesh peaches (Prunus persica L.) induced by the workup procedure. J. Agric. Food Chem. 1999, 47, $4742-4745$

(52) Polenta, G.; Budde, C.; Murray, R. Effects of different prestorage anoxic treatments on ethanol and acetaldehyde content in peaches. Postharvest Biol. Technol. 2005, 38, 247-253.

(53) Eccher Zerbini, P.; Giudetti, G.; Rizzolo, A.; Grassi, M. Harvest and quality indixes of peach. Inform. Agrario 2001, 57, 57-60.

(54) Czerny, M.; Christlbauer, M.; Christlbauer, M.; Fischer, A.; Granvogl, M.; Hammer, M.; Hartl, C.; Moran Hernamdez, N.; Schieberle, P. Re-investigation on odour thresholds of key food aroma compounds and development of an aroma language based on odour qualities of defined aqueous odorant solutions. Eur. Food Res. Technol. 2008, 228, 265-273.

(55) Leffingwell, D.; Leffingwell, J. C. Odor detection thresholds of GRAS flavor chemicals; http://www.leffingwell.com (accessed April 2010) 